PontIFícIa UNIVERSIDADE CATÓLICA dO RIO DE JANEIRO

Como a comunicação personalizada e com apelo de humor pode influenciar a atitude do consumidor

\author{
Mariana Corrêa de Godoy
}

Trabalho de Conclusão de CuRso

Centro de ciências sociais - CCS

DePARTAMENTO dE AdMINISTRAÇÃO

Graduação em Administração de Empresas 
Mariana Corrêa de Godoy

\title{
Como a comunicação personalizada e com apelo de humor pode influenciar a atitude do consumidor
}

\author{
Trabalho de Conclusão de Curso
}

Trabalho de Conclusão de Curso, apresentado ao programa de graduação em Administração da PUC-Rio como requisito parcial para a obtenção do titulo de graduação em Administração.

Orientador: João Renato de Sousa Coelho Benazzi 


\section{Agradecimentos}

Antes de tudo agradeço aos meus pais Geraldo Godoy e Pilar Godoy por terem me proporcionado a oportunidade de chegar até aqui e sempre terem prestado todo o suporte necessário, fazendo com que eu vencesse mais essa etapa na minha vida. Ao meu irmão Rodrigo Godoy, por sempre estar por perto e ter me apoiado em minhas decisões. Agradeço imensamente ao meu parceiro da vida Daniel Miranda por todos os anos de companheirismo, noites de estudo e ensinamentos divididos com tanto carinho que com certeza foram fundamentais na minha formação pessoal e profissional. Ao professor orientador João Renato de Sousa Coelho Benazzi por seu apoio no amadurecimento e orientação no tema deste estudo. Aos amigos da vida e aos grandes amigos que fiz na PUCRio que pretendo levar comigo para sempre. 


\section{Resumo}

GODOY, M C. Como a comunicação personalizada pode influenciar a atitude do consumidor. Rio de Janeiro, 2017. 33 p. Trabalho de Conclusão de Curso - Departamento de Administração. Pontifícia Universidade Católica do Rio de Janeiro.

Diante de um cenário de extrema competitividade a comunicação pode ser um diferencial competitivo, mas para isso é necessário identificar as formas na qual a comunicação personalizada ao cliente pode influenciar sua atitude. Nesse contexto, o presente trabalho busca compreender as impressões obtidas pelos clientes quando a empresa o aborda de forma mais humana e intimista. Além disso também investiga se existe uma maior tolerância por parte dos consumidores com empresas que investem nesse tipo de comunicação e se todas as faixas etárias são receptivas a esse tipo de contato. Somando essas perspectivas com a interpretação das situações na qual esse tipo de abordagem se adequa é possível discutir o potencial dessa abordagem do ponto de vista empresarial.

Palavras- chave

Atitude do consumidor, comunicação personalizada, humor

\section{Abstract}

GODOY, M C. The ways the personalized communication can influence the consumer's attitude. Rio de Janeiro, 2017. 33 p. Trabalho de Conclusão de Curso - Departamento de Administração. Pontifícia Universidade Católica do Rio de Janeiro.

Facing a high competitive scenario, the communication can be considered a competitive advantage, but it is necessary to identify the ways which the personalized communication skill can influence the consumer's attitude. In this context, this paper aims to comprehends the consumers point of view when a company reaches them in a close approach. In addition, this paper also investigates if the consumers are more tolerant to the companies that assume this kind of communication and the receptivity among the different age ranges. Understanding these perspectives and interpreting which situations the personalized communication is suitable are fundamentals to discuss the potential of this approach nowadays.

Keywords

Consumer's attitude, personalized communication, humor 


\section{Sumário}

1 O tema e o problema de estudo 1

1.1. Introdução ao tema e ao problema do estudo 1

1.2. Objetivo do estudo 2

1.3. Objetivos intermediários do estudo 2

1.4. Delimitação e foco do estudo 3

1.5. Justificativa e relevância do estudo 4

2 Revisão de literatura $\quad 5$

2.1. Comunicação personalizada no marketing digital 5

2.2. Tipos de apelo de mensagens $\quad 7$

2.3. Atitude do consumidor 9

3 Métodos e procedimentos de coleta e de análise de dados do estudo 11

3.1. Etapas de coleta de dados 11

3.2. Fontes de informação selecionadas para coleta de dados no estudo12

3.3. Procedimentos e instrumentos de coleta de dados utilizados no estudo

3.4. Formas de tratamento e análise dos dados coletados para o estudo14

3.5. Limitações do Estudo

4 Apresentação e análise dos resultados 16

4.1. Descrição 16

4.1.1. Descrição do perfil da pesquisa exploratória 16

4.1.2. Descrição do perfil da amostra da pesquisa descritiva 16

4.2. Descrição e análise dos resultados da etapa exploratória da pesquisa18

4.3. Descrição e análise dos resultados da etapa descritiva da pesquisa 20

5 Conclusões e recomendações para novos estudos 30

5.1. Sugestões e recomendações para novos estudos 31 
Anexo 1

\section{Lista de figuras}

Figura 1 - Netflix interagindo com cliente 19

Figura 2 - Nubank interagindo com cliente 19

\section{Lista de Tabelas}

\section{Lista de Gráficos}

Gráfico 1 - Percentual de respondentes por sexo ........................................ 17

Gráfico 2 - Percentual de respondentes por faixa etária .................................. 17

Gráfico 3 - Percentual de respondentes por classe social ............................ 18

Gráfico 4 - Percentual de humor por sexo ................................................ 18

Gráfico 5 - Grau de surpresa geral ........................................................ 20

Gráfico 6 - Grau de surpresa x Faixa etária................................................... 21

Gráfico 7 - Grau de surpresa x Humor........................................................ 22

Gráfico 8 - Grau de tolerância geral ....................................................... 23

Gráfico 9 - Grau de tolerância x Faixa etária .............................................. 23 
Gráfico 10 - Grau de tolerância x Sexo...................................................... 24

Gráfico 11 - Grau de tolerância x Humor .................................................. 25

Gráfico 12 - Grau de compartilhamento geral ........................................... 26

Gráfico 13 - Grau de compartilhamento x Faixa etária ................................. 26

Gráfico 14 - Grau de compartilhamento x Sexo .......................................... 27

Gráfico 15 - Grau de compartilhamento x Humor .......................................... 27 


\section{0 tema e o problema de estudo}

Esse capítulo volta-se à apresentação do tema que se pretende desenvolver e do problema de estudo.

Assim, apresenta-se o problema que suscitou a proposta de investigação e respectivos objetivos de pesquisa. Na sequência, são indicadas as suposições e as hipóteses do estudo e se informa a relevância e justificativa do estudo e a delimitação e foco do estudo.

\subsection{Introdução ao tema e ao problema do estudo}

A evolução da tecnologia trouxe consigo, mudança no comportamento do consumidor e automaticamente as empresas também precisaram se adequar. Hoje, o mundo é bem mais conectado e o acesso a informação e aos meios de comunicação são fáceis e para todos, ou seja, antes predominava uma via única de comunicação empresa com o cliente, mas hoje é possível encontrar nas mídias sociais a comunicação do cliente com a empresa. Segundo Terra (2011), a tecnologia da informação transformou a forma de comunicação entre comunicadores e seu público. Hoje, a comunicação deixa de estar só nas mãos das grandes mídias e conglomerados corporativos e passa a estar também em poder dos consumidores.

Há um tempo atrás, a comunicação entre empresas e clientes só ocorria através de SAC, call center ou quando o cliente já estava na loja e pedia para falar com o gerente. Hoje, o consumidor alcança as empresas por outros meios: redes sociais, whatsapp, e-mail, chat, telefone e se a empresa não acompanhar essa evolução pode por em risco sua reputação. Para Coutinho (2009), a imagem da marca não depende mais só dos meios tradicionais, a informação encontrada na web também tem grande influência na intenção de compra dos clientes.

Aproveitando esse gancho da aproximação com os clientes pelas novas tecnologias, algumas companhias aderiram uma nova forma de se comunicarem, diferente da formalidade comum na relação entre empresas e compradores. Passaram a adotar uma comunicação personalizada, com linguagem mais informal e muitas vezes com o apelo do humor. Para Evaldt (2015), a empresa precisa conhecer bem o seu consumidor para se comunicar com ele através das 
mídias sociais de maneira assertiva, pois nem todos os públicos irão gostar de uma comunicação que seja mais descontraída.

A partir do debate da comunicação personalizada e seus impactos percebidos pelo cliente, é possível motivar um dos principais questionamentos gerados pela reflexão: Como a comunicação personalizada e com apelo de humor ao cliente pode influenciar a atitude do consumidor?

\subsection{Objetivo do estudo}

Este trabalho tem como objetivo central avaliar a partir da pesquisa realizada em novembro de 2017, se uma comunicação mais direta, personalizada e com um apelo de humor por parte das empresas pode fazer com que o cliente mude sua atitude perante a marca.

Portanto este trabalho pretende contribuir para uma maior compreensão de como o cliente recebe esse tipo de abordagem, em que situações é aceito e se existe um perfil de cliente que está mais disposto a aceitar essa forma de comunicação do que outros.

\subsection{Objetivos intermediários do estudo}

Para se atingir o objetivo final proposto esse estudo prevê, como objetivos intermediários a serem alcançados:

Identificar quais impressões os clientes têm quando as empresas utilizam uma abordagem mais descontraída e direta. Pretende-se perceber se essa aproximação é bem recebida ou não pelos consumidores.

Investigar se os clientes são mais tolerantes a erros das empresas, quando a abordagem é mais amigável. A partir dessa investigação, busca-se entender se ao fazer a reclamação e os clientes receberem uma solução de forma amigável e descontraída, eles teriam uma maior tolerância ao erro cometido pela empresa.

Analisar se todas as gerações de clientes são tolerantes e valorizam esse

tipo de abordagem. Com isso espera-se ser possível reconhecer melhor a geração que aceita esse tipo de comportamento por parte das empresas. Entender se o público jovem está mais aberto a esse tipo de abordagem, se o público mais velho está mais disposto a lidar com esse atendimento, os dois públicos ou nenhum dos dois.

Compreender em quais situações essa abordagem se adequa. Dessa forma pretende-se discutir se os clientes só aceitam essa abordagem em 
interações comuns na internet, ou se for algo mais sério como cancelamento de conta e ações mais burocráticas também é aplicável.

Entender se o cliente costuma reagir a essa abordagem de formas diferentes de acordo com o segmento empresarial. Isso vai nos permitir compreender eventuais limitações e restrições da comunicação proposta de acordo com a área de atuação da empresa.

Reconhecer se existe alguma diferença de aceitação dessa abordagem por parte dos gêneros. Ter essa compreensão facilita o aprofundamento sobre 0 perfil do cliente que tende a ser mais receptivo a essa interação.

Decifrar se existe um meio de comunicação em que as pessoas aceitem melhor esse tipo de abordagem. Pretende-se entender se a preferência pela comunicação informal existe em algum dos meios comuns de comunicação.

Investigar o por que dos consumidores que não gostam desse tipo de tratamento pensam dessa forma. Baseado nesse entendimento pode-se traçar o perfil desses clientes e buscar uma nova abordagem para eles.

Analisar se os clientes que recebem uma resposta criativa e bemhumorada em suas solicitações estão dispostos a compartilhar essas situações em suas redes sociais.

\subsection{Delimitação e foco do estudo}

Este estudo volta-se mais especificamente para abordar a questão da comunicação personalizada das empresas com os seus consumidores sob o ponto de vista específico dos clientes.

Com o intuito de discutir essa percepção dos clientes foi realizada uma pesquisa de campo sobre como os compradores reagem frente a essa forma mais íntima de abordagem. A pesquisa foi realizada no Rio de Janeiro, Brasil, e contempla as faixas etárias, gênero, classes de renda e classes sociais.

Tal ângulo de análise se mostra interessante e importante por que podemos compreender quais impactos podem gerar a comunicação personalizada e com apelo de humor frente aos clientes. Além de podermos identificar qual perfil de cliente possuí uma maior aceitação a esse tratamento diferenciado.

Embora relevante, não se pretende tratar da questão do impacto da personalização da comunicação sob o foco das empresas já que tal perspectiva envolveria uma outra pesquisa, tornando a pesquisa abrangente sem um foco real para ser analisado. 
A escolha em delimitar o estudo apenas do ponto de vista do consumidor se deu pelo fato de ter cada vez mais empresas utilizando esses recursos na comunicação e ainda não existirem muitos artigos avaliando a perspectiva do consumidor sobre esse tema.

\subsection{Justificativa e relevância do estudo}

As informações que esse estudo pretende produzir podem se mostrar de interesse para as empresas que utilizam esse tipo de abordagem com os seus clientes pois esse artigo pode Ihes auxiliar a identificar para qual público específico essa comunicação deve ser utilizada e se deve ser utilizada.

Entre os aspectos estratégicos para as companhias será possível, avaliar se é melhor seguir nessa mesma forma de tratamento ou seguir em outra linha.

Tudo isso também auxiliará novos empreendedores que estejam na montagem de um negócio. Eles terão mais análises que dizem respeito sobre a comunicação personalizada, podendo facilitar nas tomadas de decisão sobre qual é a melhor forma de iniciar o relacionamento com os seus clientes.

Os resultados a serem alcançados também poderão ser úteis para acadêmicos que poderão utilizar o estudo como ponto de partida para realizar artigos com temas relacionados. 


\section{Revisão de literatura}

Neste capítulo são apresentados e discutidos aspectos conceituais e estudos relacionados ao tema e estudo em investigação e que servirão de base para a análise realizada.

Esta seção está dividida em três partes e abordam, respectivamente, a questão da conceituação da comunicação personalizada no marketing digital para contextualizar o problema de estudo e poder entender como essa abordagem pode influenciar a atitude do consumidor. Logo em seguida será abordado o impacto que os tipos de apelo nas mensagens podem causar no cliente. Por fim a última seção deste capítulo apresenta como se constrói a atitude do consumidor.

\subsection{Comunicação personalizada no marketing digital}

Kotler (2012), diz que o ponto de contato com o cliente é quando o mesmo se relaciona com uma marca ou produto. Essa comunicação precisa ser feita de forma minuciosa para que gere uma experiência positiva para o consumidor.

Dentre as classificações da comunicação pode-se defini-la como ativa ou receptiva. Abreu (1997) ressalta que a comunicação ativa é caracterizada quando um serviço de telemarketing, por exemplo, entra em contato com o cliente para compreender qual seu nível de satisfação com a companhia, antes que ele entre por qualquer razão. Empresas assim, possuem um melhor serviço de pós-venda deixando seus clientes mais satisfeitos. Já na comunicação receptiva são os clientes que entram em contato com a empresa. Nessa modalidade as empresas precisam estar prontas para receber as solicitações de seus clientes e solucionar seus problemas. Pelas diferenças explicitadas na conceituação, pode-se notar que cada forma de comunicação possuí suas características específicas e devem ser tratadas de formas individuais.

Analisando essas características, Mondo et al (2010) diz que o telemarketing ativo é considerado uma ação invasiva e por isso a comunicação deve ser feita de forma bem pensada e coesa para que o cliente compreenda facilmente a mensagem. Caso isso não aconteça, pode ser mais apropriado que a empresa encerre o contato para que o cliente não fique com uma imagem negativa da mesma. Em adição, Madruga (2000) ressalta que essa modalidade 
pode trazer informações importantes sobre os clientes e futuros clientes, gerando oportunidade de prospecção e de redução de riscos. Essas visões nos levam a inferir que a comunicação ativa é uma abordagem que requer cuidado, pois a partir dela pode-se perder um cliente ou ganhar um cliente engajado envolvido.

Já da perspectiva da comunicação receptiva, Barbosa (2007) diz que as reclamações são uma boa oportunidade de identificar onde a organização está errando, procurar soluções para acertar e tentar fidelizar o cliente. Além disso, Mancini (2001) explicita que o telemarketing receptivo - para ser de boa qualidade - precisa que a empresa esteja preparada com pessoal para pronto atendimento, qualificado a solucionar problemas com rapidez e que tenha ótimo conhecimento sobre o negócio. Essas perspectivas trazem a reflexão de que a companhia precisa treinar muito bem os funcionários que irão ficar na função da comunicação receptiva, pois normalmente os clientes procuram as organizações com alguma reclamação.

Outro fator de relevância da comunicação receptiva é indicado pela afirmação de Kotler (2012) de que atrair um novo cliente pode custar cinco vezes mais do que manter um já existente. Dessa forma, a atitude receptiva pode ser uma oportunidade de reverter a situação do comprador que esteja insatisfeito e garantir a sua retenção.

Ao trazer essa discussão para o meio digital, percebe-se que também pode-se aplicar esse conceito de comunicação ativa e receptiva que é usada no telemarketing. A tolerância ao tempo de resposta esperado pelos consumidores nesse meio é pequena, pois a velocidade da informação no marketing digital é uma de suas principais características. Nessa linha, introduz-se um conceito utilizado para abordar essa interação rápida das empresas com seus consumidores nas redes: $O$ marketing em tempo real.

Essa expressão é definida de três formas diferentes segundo o Digital Marketing Glossary (2014). A primeira é a automação de marketing, que seriam mensagens pré-estabelecidas e automáticas, para quando se tem um volume grande de mensagens por parte dos clientes. Esse método busca responder principalmente dúvidas recorrentes, além de monitorar a citação do nome da marca nas redes. Já a segunda, está ligada a eventos especiais, como por exemplo, copa do mundo, a premiação do Oscar e o dia das mães. As companhias podem aproveitar essas datas para gerar uma oportunidade de interação com os clientes nas redes. Essa interação precisa ser feita com cautela para que não associe o nome da marca a algum evento que tenha tido 
alguma repercussão negativa. O terceiro e último conceito são as ações pontuais de marketing em tempo real. A empresa faz sua abordagem ao público com campanhas nas redes e utilizam um relatório para entender o alcance dessa abordagem. Normalmente, essa opção é utilizada para se alcançar públicos específicos e conseguir uma interação diferenciada com os consumidores.

Entre as três definições descritas anteriormente existe algo em comum. Del Rowe (2016) diz que o marketing de tempo real ideal é o que os consumidores não percebem que está sendo feito para atraí-los, eles estão navegando na internet e eis que encontram algo que julgam interessante.

Toda discussão conceitual anterior faz notar que as redes sociais se tonaram um ambiente eficaz de comunicação das empresas com os consumidores. Essa abordagem atual em que as corporações estão tendo que se adaptar para acompanhar o avanço dos meios de comunicação no ambiente digital, é essencial para que a mesma tenha uma conexão com os seus clientes e os entenda melhor. A partir do momento que as empresas passarem a entender as reinvindicações, o perfil e os desejos de seus consumidores poderão passar a oferecer serviços e produtos cada vez mais personalizados, gerando uma maior fidelização.

Ribeiro \& Soares (2015) dizem que a customização e personalização da mensagem costuma agradar os consumidores de forma a salientar seus desejos pessoais e necessidades, o que difere da comunicação do marketing de massas, que trata os consumidores de forma indiferenciada. Esse apelo a uma abordagem construída a um cliente especifico pode ser uma boa tática para retenção e fidelização dos clientes, pois a partir dessa interação os consumidores passam a se sentir protagonistas para a marca.

Outro conceito que tem sido muito usado pelos profissionais de marketing para essa atuação das marcas nas redes sociais é o SAC 2.0.

\subsection{Tipos de apelo de mensagens}

As mensagens personalizadas das empresas para seus clientes podem ter os mais diferentes apelos. Silva (2010) define apelo como tudo que seja diferente e interessante de forma a chamar a atenção e sensibilizar a emoção e a consciência do individuo. Essas mensagens podem mexer com os sentimentos, tocando o coração ao emocionar ou fazer rir, deixando os consumidores alertas e curiosos pelo que está por vir, de acordo com Solomon (2016). Dentre os tipos de apelos utilizados na comunicação é possível separar as alternativas que possuem o apelo humorístico, emocional e racional, sexual e de medo. 
O autor (2016) fala que uma comunicação engraçada faz com que a probabilidade que os consumidores tenham uma melhor aceitação da mensagem seja maior, porque esse tipo de abordagem inibe o pensamento a respeito do que eles não gostaram na mensagem. Silvia (2016) define o humor como uma forma de persuasão, pois mensagens com esse apelo tem um papel importante de atrair a atenção dos consumidores e reter a informação da comunicação por mais tempo. Então pode-se perceber que a comunicação feita com essa intenção é criativa e com um tom mais descontraído para poder gerar uma maior aproximação dos consumidores e reverter possíveis situações de reclamação.

Para Solomon (2016) as mensagens com apelo emocional e racional são de difícil mensuração embora a lembrança do conteúdo de mensagens que envolva "pensamento" tenda a ser melhor das que envolvem "sentimento". Isso ocorre porque pode ser difícil de perceber as reações dos consumidores quando se é utilizado o apelo emocional. Já Kotler (2015) dizem que os apelos racionais são os que os consumidores têm interesse, pois são aqueles que vão trazer o benefício desejado. O autor (2015) dizem também que algumas pessoas acreditam que o apelo emocional tem um maior poder de persuasão porque a emoção vem antes do pensamento.

Uma outra abordagem é do apelo sexual. Para Schiffman \& Kanuk (2000) a reação do consumidor com anúncios desse tipo é difícil de ser prevista. Entretanto algumas empresas acreditam que esse tipo de interação tem o poder de chamar a atenção do consumidor. Os autores (2000) dizem também que alguns psicólogos afirmam que o apelo sexual pode ativar no subconsciente dos consumidores um desejo de adquirir o que está sendo oferecido pela marca. Solomon (2016), entretanto, diz que uma imagem provocante pode chamar atenção além do que se espera, levando o consumidor a esquecer o anúncio proposto.

O último apelo a ser abordado é o do medo, que costuma mostrar quais as consequências irão acontecer caso o consumidor não mude certa atitude, segundo Salomon (2016). Schiffman \& Kanuk (2000) dizem que quando a mensagem transmitida gera um medo intenso, se faz com que o consumidor ou rejeite a mensagem ou a prática, levando-o a experimentar uma dissonância cognitiva.

Pela diversidade de características dos apelos anteriormente discutidos, pode ser bem estratégico definir qual o melhor tipo de apelo e como utiliza-lo na mensagem a ser passada. Assim espera-se que a mensagem seja 
compreendida da maneira proposta inicialmente para os consumidores, evitando qualquer complicação posterior, seja por falta de entendimento do consumidor ou meramente pelo fato da mensagem transmitida pela empresa não ter sido bem colocada.

\subsection{Atitude do consumidor}

Os consumidores possuem opiniões variadas sobre os assuntos ligados as organizações. A cada vez que os clientes expressam o que pensam sobre determinado assunto, estão tendo atitudes. Essas atitudes podem ser de caráter positivo ou negativo.

Solomon (2016) define atitude como tudo o que podemos avaliar de forma duradoura, pois essa atitude pode se manter ao longo do tempo, e genérica, pois ter uma atitude uma vez não quer dizer que o individuo terá a mesma atitude com outros eventos parecidos. Essa avaliação pode ser feita sobre pessoas, objetos, anúncios e problemas. Já Schiffman \& Kanuk (2000) definem atitude como resultados de processos psicológicos podendo ser definidas a partir das ações tomadas pelas pessoas. Essas atitudes irão refletir se o individuo está mais tendencioso ou não para algum objeto. Apesar dessas e de inúmeras definições encontradas na literatura, Barreiros (2010) ressalta que existem três fatores comuns dentro dessas conceituações.

O primeiro fator diz que a atitude é construída através da história do indivíduo, suas experiências e vivências. O que mostra ser coerente, pois cria-se convicções e preconceitos a partir de situações anteriores vivida pela pessoa. $O$ segundo fator atribui as atitudes a um objeto, um individuo ou a uma situação. Por último, o terceiro fator diz que a atitude vem de uma situação de avaliação. O indivíduo estará avaliando algo, para a partir de então tomar uma atitude.

A própria definição de atitude discutida anteriormente já demonstra que é um objeto complexo de estudo. Para melhor compreender os impactos desse conceito, Salomon (2016) apresenta a hierarquia de efeitos que aplica qual elemento vem primeiro conhecer, sentir ou fazer. Para entender qual a diferença que faz na ordem desses elementos temos três diferentes hierarquias.

A primeira é a hierarquia de aprendizagem padrão que diz que o individuo primeiro cria crenças sobre um produto, para depois se envolver com esse produto e por fim comprar. Já a segunda é a hierarquia de baixo envolvimento que diz que o consumidor não reflete muito antes de escolher certa marca. $O$ consumidor simplesmente toma a decisão baseado nos conhecimentos que já possuí, compra o produto e após isso irá formar opinião a respeito do produto 
por estar vivendo a utilização. Por último a hierarquia experiencial aborda o fato de que o consumidor primeiro cria uma relação emocional com o produto, por isso acaba optando por ele e após a compra ele pode passar criar crenças. Essa ligação emocional pode ser por exemplo, uma embalagem divertida, nome legal do produto, entre outros aspectos.

Partindo da explicação de Solomon (2016) pode-se relacionar que a atitude do consumidor frente a marca vai influenciar no apelo da mensagem que as organizações devem utilizar com cada perfil de cliente. Baseado nisso, esperase que um comprador que se envolve emocionalmente com a marca está mais disposto a ter um diálogo em um formato mais informal do que o comprador que não tem nenhum envolvimento com a marca.

Após compreender o que é a atitude, Salomon (2016) chega ao conceito de modelos de atitude. Esses modelos identificam características para tentar prever a atitude do consumidor. O modelo de atitude mais utilizado é o modelo de Fishbein, esse modelo avalia três componentes de atitude que são crenças, vínculos e avaliação.

As crenças são conhecimentos já adquiridos sobre o produto, pensamentos construídos previamente pelo consumidor. Os vínculos são o elo entre o objeto e seus atributos. Por último a avaliação é feita sobre cada atributo importante dos objetos. Após esses três elementos serem associados, é possível chegar no cálculo da atitude geral de um consumidor em relação a um objeto.

As organizações podem utilizar os resultados desses modelos de atitude para poder melhorar os seus negócios. A partir do resultado pode ser possível compreender quais atributos são necessários melhorar na corporação e quais já são muito bem avaliados pelo consumidor. Será possível perceber também se há uma oportunidade para acrescentar um novo atributo. Todas essas avaliações podem fazer com que a organização fique com um valor maior na atitude geral de mais consumidores. 


\section{Métodos e procedimentos de coleta e de análise de dados do estudo}

Este capítulo pretende informar sobre as diversas decisões a cerca da forma como este estudo foi realizado.

Está dividido em cinco seções que informam, respectivamente, sobre as etapas de coleta de dados do estudo realizado, sobre as fontes de informação selecionadas para coleta de informações neste estudo. Na seqüência, informase sobre os processos e instrumentos de coleta de dados realizados em cada etapa, com respectivas justificativas, sobre as formas escolhidas para tratar e analisa os dados coletados e, por fim, sobre as possíveis repercussões que as decisões sobre como realizar o estudo impuseram aos resultados assim obtidos.

\subsection{Etapas de coleta de dados}

Este trabalho possui duas etapas de coleta de dados no campo. A primeira etapa consistiu em uma pesquisa exploratória que se aproximou bastante de uma pesquisa netnográfica pois foi feita observação documental de situações ocorridas no ambiente virtual. Esse método de pesquisa foi escolhido para auxiliar na compreensão de como os perfis de consumidores reagem a abordagem direta das empresas nesse ambiente. Além disso, também teve como intenção compreender como é a reação do consumidor a partir das interações feitas pela marca.

A segunda etapa foi composta de pesquisa descritiva. Esse tipo de pesquisa busca diagnosticar o problema questionado, afim de identificar frequência e padrões no que está sendo estudado. Essa estratégia foi escolhida por auxiliar a enxergar e entender de forma mais profunda hipóteses concretas para o problema de estudo. Foi realizado um questionário, no período de 29 de outubro a 2 de novembro de 2017 e feita com a intenção de avaliar - através da coleta de dados primários - qual a opinião dos consumidores ao serem abordados de forma descontraída e direta pelas empresas através de redes sociais e outros meios que propiciem esse tipo de comunicação. Com o resultado dessa pesquisa busca-se entender qual é o público que aceita melhor esse tipo de abordagem e em quais ocasiões ela pode ser usada. 


\subsection{Fontes de informação selecionadas para coleta de dados no estudo}

$\mathrm{Na}$ primeira etapa buscou-se informações na internet através da observação documental, principalmente em redes sociais, como por exemplo: Facebook, Instagram e Twitter. A abordagem das empresas nesse ambiente permite uma maior interação interpessoal, dando a abertura para que as companhias possam ter uma relação mais próxima com seus clientes. A investigação nesse ambiente proporcionou encontrar muitos dados secundários, que foram situações em que as empresas interagiram com seus consumidores de forma descontraída informal e com apelo humorístico.

Tendo adquirido essas informações, foi possível investigar e avaliar como tem sido feita a abordagem das empresas e qual é a reação dos consumidores a esse tipo de comunicação. Essa primeira parte da pesquisa teve como objetivo ter a compreensão de qual público tem o costume de interagir com as empresas e quais tipos de reações são as mais comuns entre eles.

$\mathrm{Na}$ segunda etapa da pesquisa, a quantidade da amostra foi de 436 pessoas com a margem de erro de $5 \%$. O questionário foi aplicado para um público de diferentes faixas etárias com idade variando de menos de 20 anos de idade até mais de 60 anos de idade, sexo feminino e masculino, Todas as classes sociais, sendo elas A, B, C, D e E e pessoas com todos os tipos de humor, variando de péssimo a ótimo humor. A seleção de respondentes dessa etapa não teve nenhum tipo de critério específico, a intenção era conseguir uma amostra bem variada, com ambos os sexos, faixas etárias e classe social.

\subsection{Procedimentos e instrumentos de coleta de dados utilizados no estudo}

Na primeira etapa as informações foram colhidas utilizando-se a análise do ambiente virtual, através da pesquisa documental a fim de encontrar exemplos de interações e reações dos consumidores às abordagens feitas pelas marcas. Essa análise que pode ser comparada a uma análise netnográfica, busca entender como funciona esse relacionamento do consumidor com a empresa no ambiente virtual e o quão efetivo esse tipo de comunicação pode ser na mudança do comportamento do consumidor. Foi feita uma intensa busca nas redes sociais em empresas que possuem a fama de utilizarem esse tipo de comunicação mais humana e descontraída com os seus clientes, afim de encontrar alguns exemplos e entender quais situações mais se repetiam e qual era o perfil mais comum do público que costuma participar. 
$\mathrm{Na}$ segunda etapa, o instrumento utilizado foi o questionário online que pode ser lido completo no Anexo 2. Aplicou-se o questionário por meio de uma ferramenta chamada Qualtrics que disponibiliza a pesquisa online. $O$ questionário foi divulgado através de um link que foi enviado diretamente para conhecidos, amigos e familiares através do Whatsapp com mensagens pessoais e personalizadas. Também foi colocado na página pessoal de uma popular rede social e no grupo dos alunos de administração da PUC-Rio. Além disso pessoas conhecidas e amigos auxiliaram na divulgação enviando para outras pessoas. $O$ link da pesquisa ficou disponível por cinco dias e a divulgação durou esse mesmo período.

O questionário foi escolhido por que era interessante alcançar um grande volume de respondentes afim de aumentar a confiabilidade dos resultados e a partir desse método é possível divulgar de forma prática e acessível para um grande número de pessoas.

As questões do questionário foram construídas da seguinte forma: primeiro vinham três perguntas situacionais, que explicitava três diferentes casos e buscavam entender o grau de surpresa, grau de tolerância e o grau de compartilhamento por parte dos respondentes. Essas três perguntas iniciais foram feitas afim de responderem alguns dos objetivos intermediários do estudo. Em seguida vinha uma pergunta sobre os meios de comunicação utilizados pelo respondente. Essa pergunta tinha como intenção entender quais os meios de comunicação são mais utilizados por pessoas que aceitem melhor a comunicação personalizada.

Em seguida, vinham duas escalas Likert: a primeira indagava aos respondentes quais eram os momentos adequados para a utilização da comunicação personalizada por parte das empresas. Essa escala também tinha como intenção responder um dos objetivos intermediários. A segunda utilizada foi a MSHS - Escala multidimensional do senso de humor, desenvolvida e validada estatisticamente por Thorson \& James (1993). Utilizou-se como referência a aplicação feita por José \& Parreira (2008), uma adaptação para português de Portugal da MSHS com algumas correções para o português do Brasil. Essa escala busca julgar a partir de 24 respostas o humor do informante. Com esse resultado a intenção é relacionar o humor dos respondentes com as demais respostas e entender se o humor afeta a aceitação a comunicação personalizada. Para terminar vinham as perguntas de perfil demográfico que eram idade, gênero e faixa de renda. Com esses dados objetivo era 
compreender se algum grupo especifico de faixa etária, gênero ou renda é mais flexível com esse tipo de comunicação.

\subsection{Formas de tratamento e análise dos dados coletados para o estudo}

$\mathrm{Na}$ primeira etapa utilizou-se o método de análise de conteúdo. conteúdo investigado nas redes sociais, foi analisado através de observação de quais questões eram mais recorrentes na comunicação personalizada nesses meios de comunicação. Essa investigação foi importante para construção da segunda etapa da pesquisa, contribuindo para a contextualização e construção de perguntas situacionais.

$\mathrm{Na}$ segunda etapa, optou-se por fazer uma análise descritiva dos dados coletados comparando os diferentes grupos existentes na amostra entre si. Além dessa análise descritiva também foi feito $o$ teste $z$ para certificar que a comparação proporcional entre as amostras das questões um, dois e três do questionário além do humor tinha validade estatística. Os resultados deste teste podem ser analisados no Anexo 1.

$\mathrm{Na}$ literatura encontrada sobre a escala MSHS, os esforços são direcionados para estudos de seus fatores, ou seja, como um grupo de respostas se comportam entre si. Entretanto no presente trabalho buscou-se interpretar as diferenças de respostas entre grupos de respondentes com a pontuação total. Em seu trabalho, Thorson \& James (1993) separaram a amostra em quartis para compreender diferenças entre o primeiro e o terceiro quartil. Seguindo a proposta dos autores (1993), optou-se por agrupar a amostra em quatro diferentes classificações.

O primeiro grupo é referente aos denominados péssimo humor e incluem os elementos que variam do valor mínimo até o primeiro quartil. O grupo seguinte é designado aos intitulados de mau humor e abrange os elementos que variam do primeiro quartil até a mediana. Depois vem o grupo dos chamados de bom humor que incluem os elementos que variam da mediana até o terceiro quartil. Por último o grupo dos nomeados de ótimo humor que contém os elementos que variam do terceiro quartil até o valor máximo.

Esse agrupamento foi essencial para a que fosse possível a interpretação da MSHS com as demais variáveis.

\subsection{Limitações do Estudo}

Nesse estudo há uma limitação na utilização da escala MSHS. Essa escala foi originalmente criada para aplicações clínicas, por isso seu estudo na área do 
marketing pode ser discutível. Além disso, existem alguns autores que defendem que o humor não deve ser medido de forma numérica, causando divergência sobre a ferramenta desenvolvida, mesmo com a comprovação estatística necessária feita pelos seus autores.

Ainda sobre a MSHS, a divisão em quartis torna sensível a nota de corte, pois com apenas um ponto de diferença a pessoa pode deixar de ser considerada bem-humorada para ser considerada mal-humorada. Entretanto esse método de agrupamento possibilitou a comparação de diferentes perfis da amostra da pesquisa.

Além disso, os pesquisados podem não ter sido verdadeiros em suas respostas por diversos motivos como não terem entendido as perguntas ou por influência externa. Para minimizar esses fatores as perguntas foram elaboradas da forma mais claras possível, para que houvesse um entendimento do informante. 


\section{Apresentação e análise dos resultados}

Este capítulo, organizado em três seções apresenta e discute os principais resultados alcançados, analisa e discute suas implicações e produz sugestões sobre o estudo previamente selecionado.

A primeira seção apresenta e descreve o perfil observado dos consumidores que interagem com as marcas nas redes sociais e também o perfil dos respondentes da amostra na pesquisa quantitativa.

A seguir trata-se da descrição e análise dos resultados da observação feita na etapa exploratória da pesquisa.

Por fim, a terceira e última seção aborda a descrição e análise dos resultados obtidos na etapa descritiva da pesquisa.

\subsection{Descrição}

\subsubsection{Descrição do perfil da pesquisa exploratória}

$\mathrm{Na}$ etapa exploratória percebeu-se que nas páginas escolhidas para observação que foram a páginas verificadas da Netflix, Nubank, Centauro e Netshoes, os principais usuários que interagiam com as empresas nas redes sociais eram jovens de ambos os sexos. Não é possível distingui-los por classe social e tipos de humor através desse método.

\subsubsection{Descrição do perfil da amostra da pesquisa descritiva}

A pesquisa quantitativa obteve um total de 436 respostas e foi realizada com uma amostragem aleatória, alcançando, portanto, ambos os sexos, todas as faixas de renda e faixas de idade variada.

A pesquisa teve uma parcela um pouco maior de respondentes do sexo feminino em relação ao sexo masculino como é possível notar no Gráfico 1. 


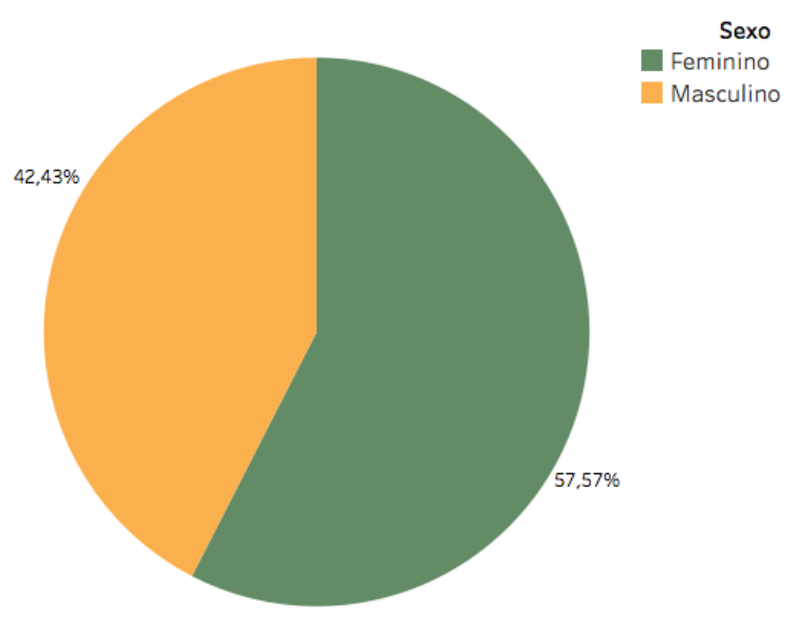

Gráfico 1 - Percentual de respondentes por sexo

As faixas etárias foram divididas em seis grupos de dez em dez anos, sendo assim foram utilizados os seguintes grupos: Pessoas com menos de 20 anos, de 21 a 30 anos, de 31 a 40 anos, de 41 a 50 anos, de 51 a 60 anos e com mais de 60 anos. A faixa de idade predominante dos respondentes foi a de 21 a 30 anos e a menos presente entre o grupo foi a de pessoas com menos de 20 anos como podemos ver no Gráfico 2.

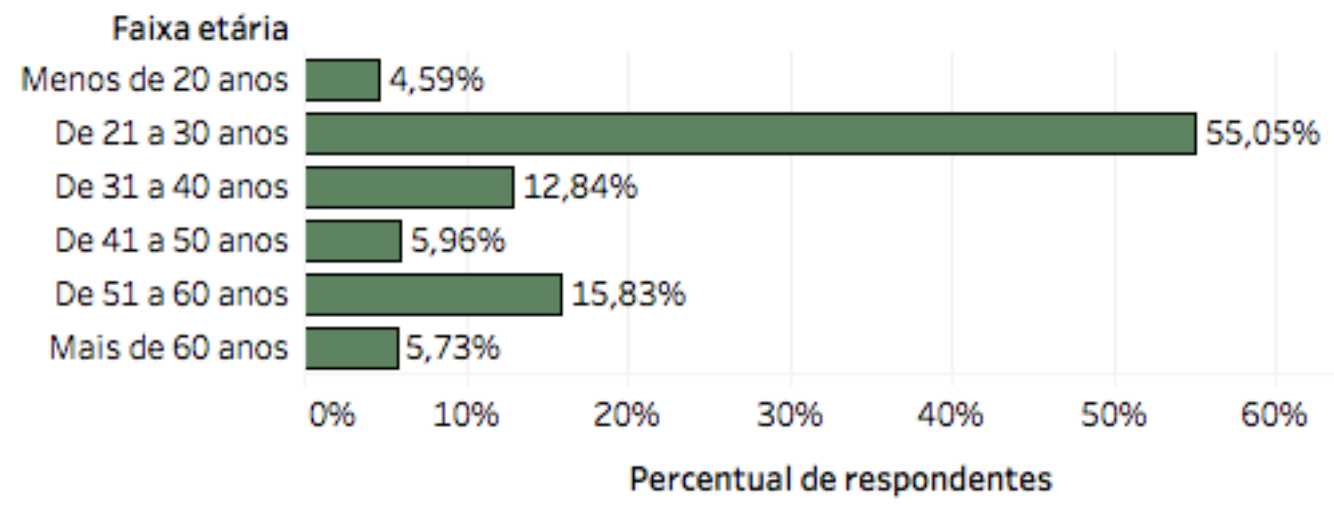

Gráfico 2 - Percentual de respondentes por faixa etária

Da perspectiva da faixa renda foi utilizada a classificação sugerida pelo IBGE, que divide as classes dentro de cinco classes que são: Classe A: Renda familiar de $\mathrm{R} \$ 18.740,01$, Classe $B$ : Renda familiar de $\mathrm{R} \$ 9.370,01$ a $R \$ 18.740,00$, Classe C: Renda familiar de $R \$ 3.748,01$ a $R \$ 9.370,00$, Classe $D$ : Renda familiar de $\mathrm{R} \$ 1,874,01$ a $\mathrm{R} \$ 3.748,00$ e Classe $\mathrm{E}$ : Renda familiar de até $\mathrm{R} \$ 1874,00$. Como é possível observar no Gráfico 3, na amostragem da pesquisa a classe $C$ foi a predominante entre os respondentes seguida da Classe B. A Classe $E$ foi a que teve menor visibilidade dentro dessa amostragem. Para auxiliar na interpretação gráfica e analise dos dados, optou-se por agrupar as classes $A$ e $B$ em um grupo e as classes $C, D$ e $E$ em um outro. 


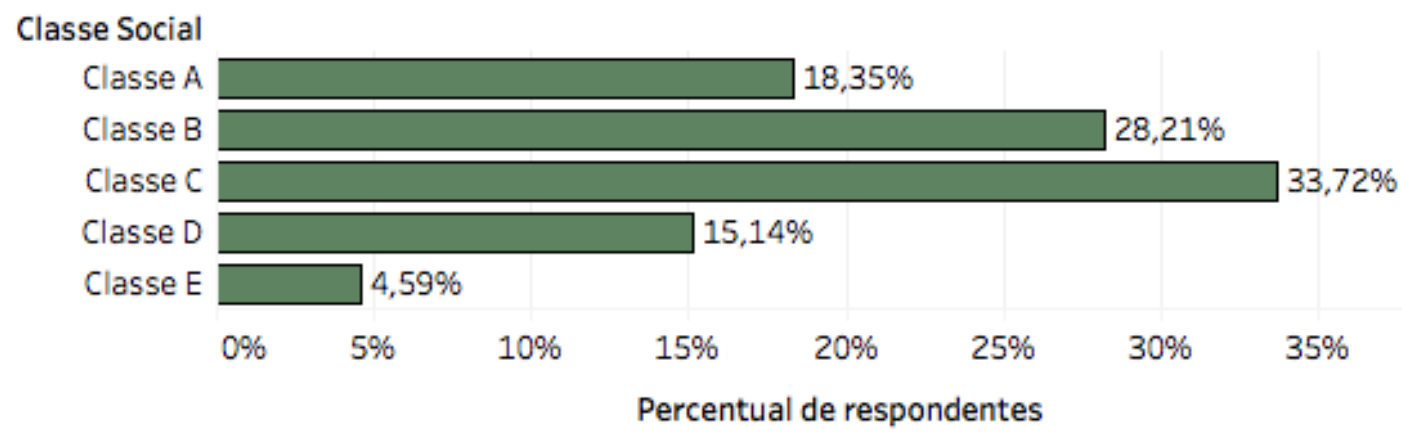

Gráfico 3 - Percentual de respondentes por classe social

Por último, foi avaliado o humor dos respondentes através da escala MSHS. A amplitude de resultados foi de 51 a 120 pontos (com apenas um respondente chegando no valor máximo). A média de resultado foi de 91,7 com desvio padrão 11,6 pontos. A mediana foi de 91,5 , com o primeiro e terceiro quartil, respectivamente tendo 84,75 e 99,25 pontos. Esses resultados são relevantes pois o agrupamento dos resultados da escala levam em consideração alguns desses cálculos estatísticos, conforme explicado na seção 3.4.

No Gráfico 4, é possível observar os diferentes níveis de humor referente a homens e mulheres. A partir da análise nota-se que as mulheres podem ser consideradas um pouco mais mal-humoradas que os homens.

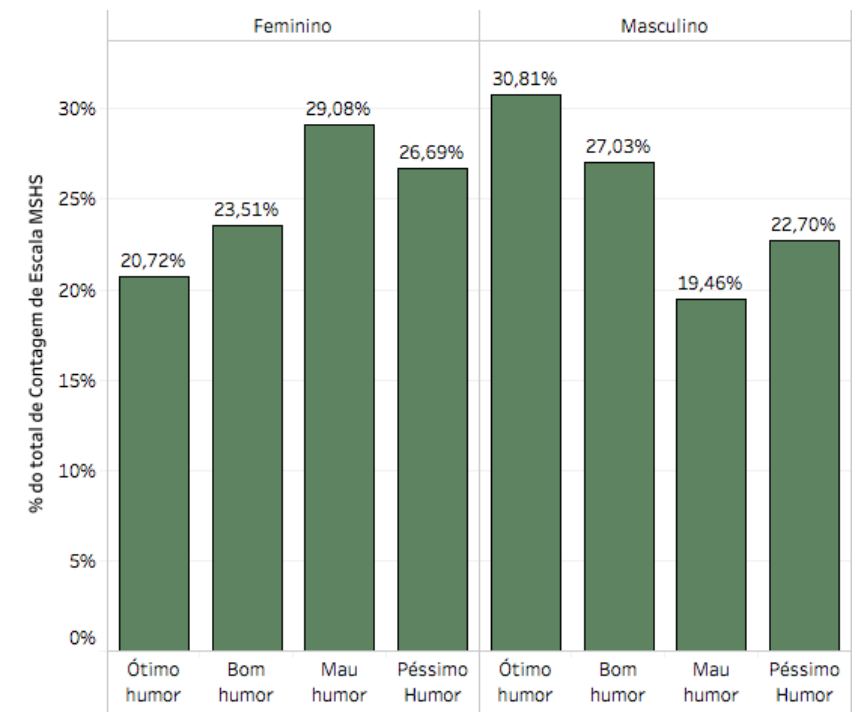

Gráfico 4 - Percentual de humor por sexo

\subsection{Descrição e análise dos resultados da etapa exploratória da pesquisa}

Na etapa exploratória, foi possível notar que muitas empresas já investem em ter suas páginas verificadas nas redes sociais. Ao buscar o nome de diversas empresas é possível encontra-las e normalmente interagindo e correspondendo aos consumidores em tempo real. A partir dessa pesquisa foi 
observada principalmente a interação de duas empresas que utilizam a comunicação personalizada nas redes sociais com seus clientes. Essas empresas foram: A Netflix, que é uma empresa de serviços de streaming de filmes e séries e o Nubank que é uma startup de serviços financeiros.

Através da observação foi possível perceber que a interação por parte de ambas empresas é feita principalmente no momento de tirar dúvidas dos consumidores ou quando eles fazem qualquer tipo de comentário em uma postagem feita pelas companhias nas redes sociais. Essa interação na maior parte das vezes é realizada utilizando linguagem descontraída, intimista e com apelo de humor. Os comentários com algum tipo de reclamação são minoria e normalmente vem seguido de uma mensagem pedindo para entrar em contato, sem fazer humor ou brincadeiras.

Na Figura 1 e na Figura 2 é possível ver dois exemplos dessas interações que ocorreu com cada das empresas. A primeira delas é um exemplo do uso do humor na Netflix e a segunda é um exemplo de como a empresa age quando é um caso de reclamação. A identidade dos consumidores foi preservada, nas imagens.

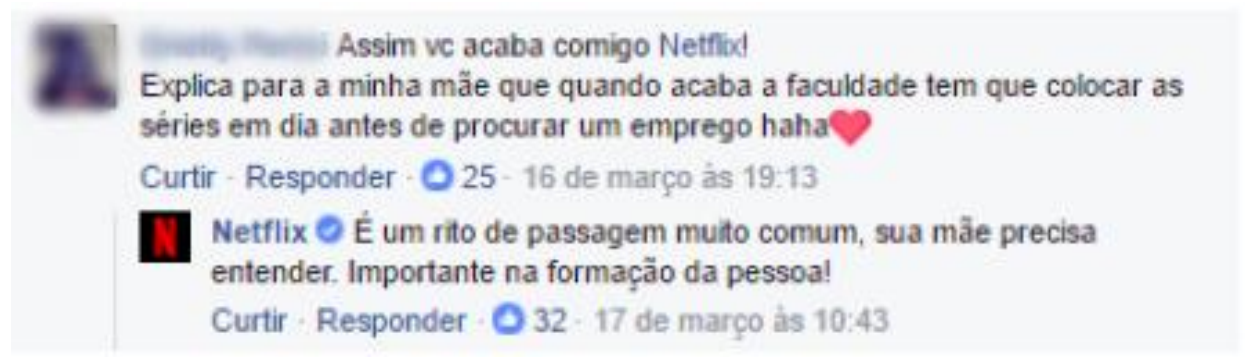

Figura 1 - Netflix interagindo com cliente

O status do meu cartão diz que está em produção. Ele deve está sendo feito a mão.

Curtir - Responder + $: 017 \cdot 19$ de setembro às 18:21

(10 Nubank $\odot$ Chama a gente por inbox que vamos te ajudar, Ivan!

Curtir - Responder - 19 de setembro às 21:03

$\rightarrow$ Ver mais respostas

Figura 2 - Nubank interagindo com cliente

Os dados obtidos nessa etapa de observação foram importantes para ajudar na construção do questionário e perceber quais pontos eram necessários ser explorados para se alcançar as respostas dos objetivos intermediários. 


\subsection{Descrição e análise dos resultados da etapa descritiva da pesquisa}

As três primeiras perguntas eram relacionas a questões situacionais. A primeira indagação pedia para que o respondente imaginasse a situação na qual seu cartão de crédito é comido pelo seu cachorro e após entrar em contato com o banco para explicar a situação, recebesse em sua casa um novo cartão com um presente também para o cachorro e uma carta feita a mão assinada por toda equipe. A pessoa tinha a opção de escolher um valor entre 1 e 5 , sendo 1 não se surpreender com a situação e 5 se surpreender muito. O objetivo desse questionamento é de compreender qual impressão os consumidores têm quando as empresas utilizam abordagem mais descontraída e personalizada.

Para realizar a análise os valores 1 e 2 da escala foram agrupados para serem compreendidos como a reação de pessoas que não se surpreenderiam, o valor 3 fica como um critério intermediário enquanto o 4 e 5 também foram agrupados para serem avaliados como a reação de pessoas que se surpreenderiam. No gráfico 5 , pode-se observar que a grande maioria das pessoas se surpreenderiam com uma situação como a descrita na primeira pergunta.

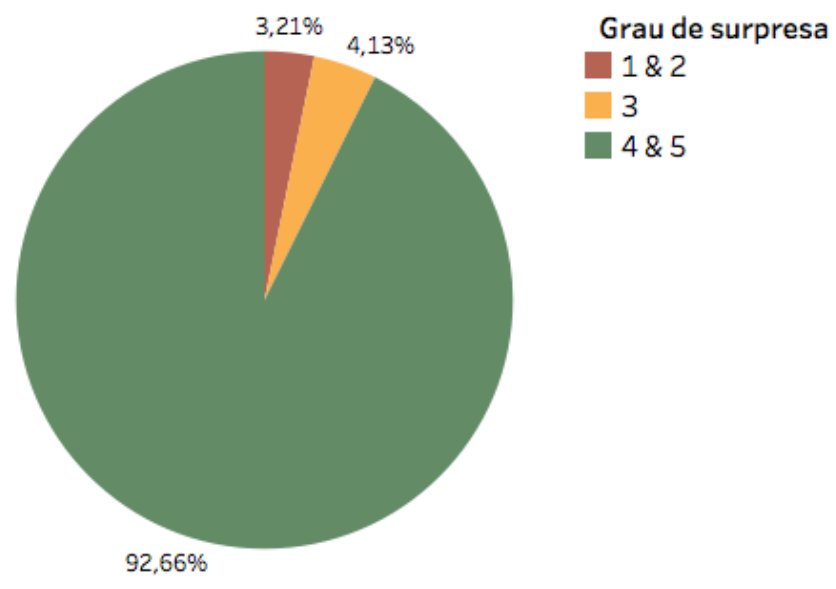

Gráfico 5 - Grau de surpresa geral

Dentre os respondentes mais de $90 \%$ respondeu $4 \& 5$, pois estes se surpreenderiam com uma interação por parte das empresas, isso pode significar que quando as interações são bem-feitas podem ter um impacto muito positivo sobre os clientes. Esse resultado vai de encontro com a afirmação feita por Ribeiro \& Soares (2015) que disse que os consumidores costumam gostar da customização e personalização da mensagem.

Ao abrir essas respostas para avaliarmos o grau de surpresa de acordo com cada sexo, não se percebe nenhuma mudança de atitude relevante. Tanto 
os homens quanto as mulheres mantêm os seus graus de surpresa em torno de aproximadamente $90 \%$ das respostas.

Quando se relaciona o grau de surpresa com a idade dos respondentes, é possível notar que apesar de ter apenas cerca de $3 \%$ de respostas negativas a surpresa, dentre essas pessoas $86 \%$ delas possuem mais de 40 anos de idade. No Gráfico 6, pode-se observar a queda do grau de surpresa a medida que a idade avança.

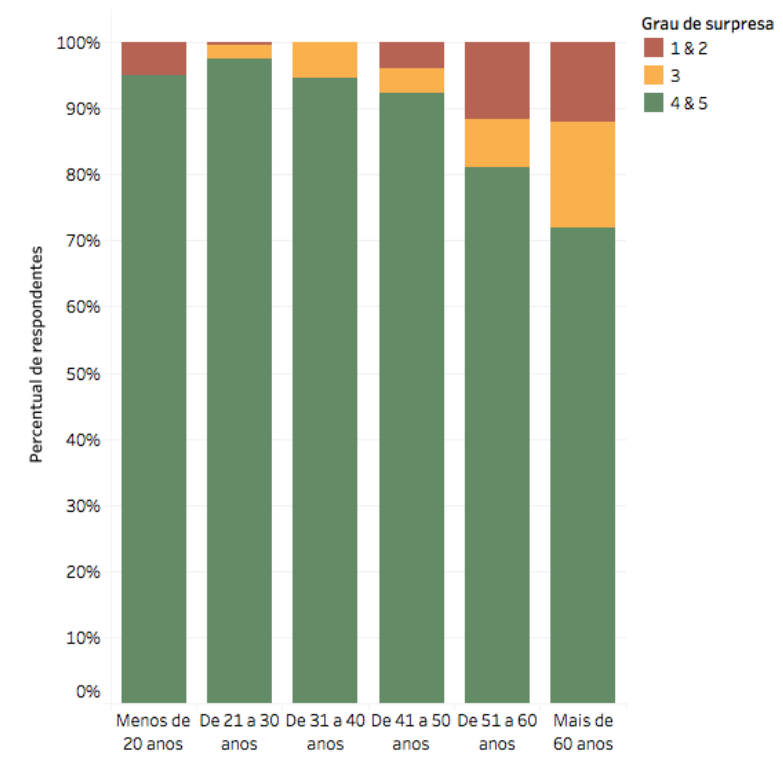

Gráfico 6 - Grau de surpresa x Faixa etária

A partir dessa observação, esse público nessa faixa etária pode ser um ponto de atenção para marcas, pois podem ser pessoas mais sensíveis a comunicação personalizada.

Assim como ocorrido na relação do grau de surpresa com cada sexo, a relação com as classes sociais também não apresentou nenhuma mudança significativa. Em torno de $90 \%$ das respostas de todas as classes sociais é de que os respondentes teriam um alto grau de surpresa.

Outra variável usada para análise com a relação do grau de surpresa foi a escala MSHS, através desses dados pode-se notar que mesmo as pessoas com péssimo humor em sua grande maioria não se sentiriam surpresos, como notase no Gráfico 7. 


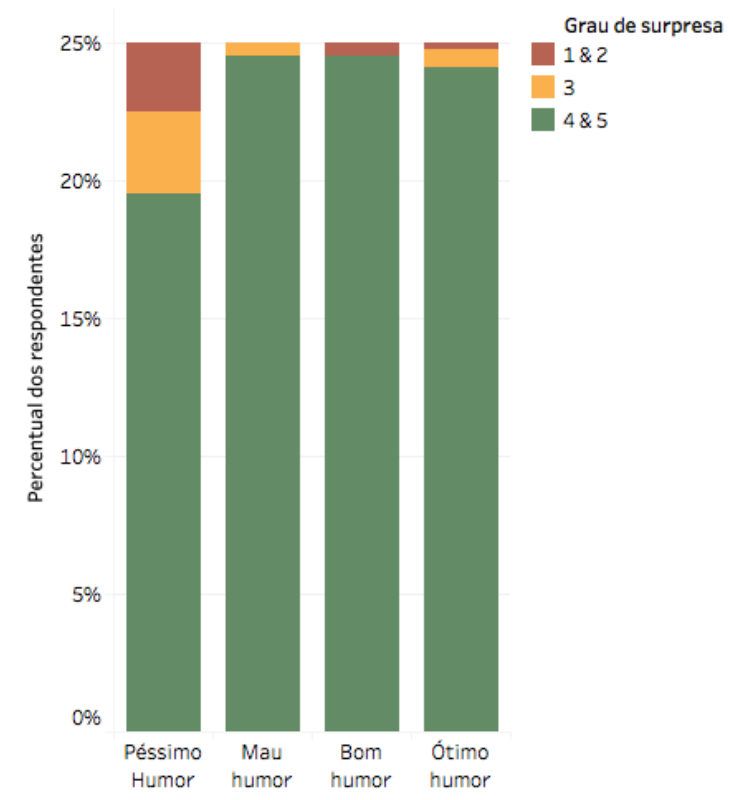

Gráfico 7 - Grau de surpresa x Humor

Esse tipo de comportamento pode demonstrar que se as organizações fizerem as abordagens de forma bem planejada, pode conseguir agradar a públicos de todos os tipos de humor.

A segunda pergunta situacional questionava ao respondente o quanto ele seria mais tolerante ao erro de uma empresa que se preocupa em falar com ele de forma mais humana e personalizada. Se caso aquele mesmo banco citado na pergunta anterior cometesse um erro como por exemplo cobrar duas vezes um mesmo valor numa escala que iria de 1 até 5 , sendo 1 indicação de não tolerar e 5 de alta tolerância.

Para realizar essa análise foi agrupado os itens 1 e 2 da escala para serem avaliados como a reação dos respondentes de não tolerar, 3 ficou como um item médio e os itens 4 e 5 também foram agrupados para serem avaliados como a reação de tolerar. No Gráfico 8 , é possível observar que a distribuição de votos nessa categoria ficou bem equilibrada, sendo a opção 4 \& 5 a categoria que recebeu a maior quantidade de escolha, ou seja, as pessoas seriam mais tolerantes com a companhia. 


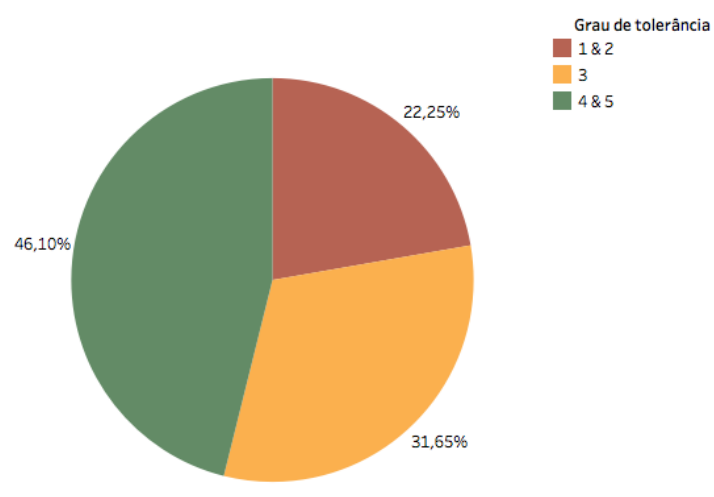

Gráfico 8 - Grau de tolerância geral

Cerca de $46 \%$ dos respondentes teriam uma maior tolerância ao erro caso a empresa utilizasse abordagens mais humanas nos seus meios de comunicação com os clientes. Já aproximadamente 32\% dos entrevistados mostraram ter média tolerância a essa mesma situação. Com isso pode-se concluir que quase $80 \%$ dos respondentes teriam uma maior tolerância aos erros da empresa devido aos esforços da comunicação personalizada, isso nos mostra que esse tipo de investimento pode ter impacto em outras áreas do negócio, como a retenção de clientes e o suporte ao consumidor.

Ao relacionar o grau de tolerância com a faixa-etária pode-se observar que dentre todos os grupos de idade a maioria dos respondentes teriam uma alta ou média tolerância ao erro. Dentre o grupo contrário, prevalece os respondentes de 41 a 50 anos. Como podemos observar no Gráfico 9.

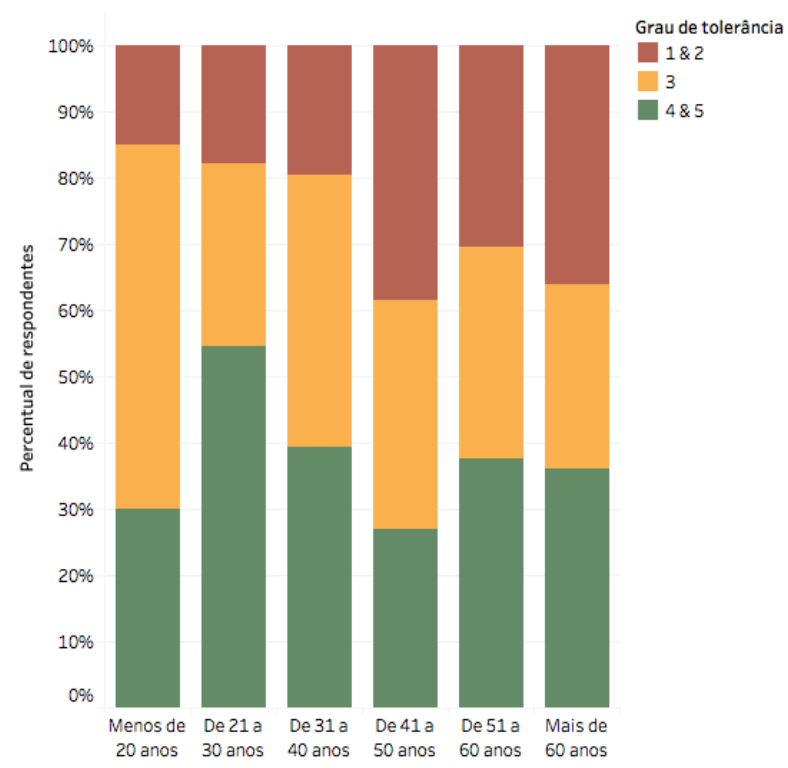

Gráfico 9 - Grau de tolerância x Faixa etária

Com essa informação, parece fazer sentido que a partir dessa idade mesmo com investimento em comunicação personalizada esse grupo de pessoas vai se tornando menos tolerantes a erros por parte das organizações. 
Outra curiosidade obtida sobre esse grupo é que eles também foram o único grupo em que a resposta para baixa tolerância prevaleceu as demais respostas. Isso só confirma a hipótese de que esse grupo pode não ser tão impactado com a comunicação para tolerar algum erro cometido. Uma teoria para isso, pode ser que essa faixa-etária seja a mais estressada e ativa no trabalho.

Ao analisar o grau de tolerância com o sexo, obteve-se um resultado curioso. Diferentemente do ocorrido na relação do grau de surpresa que não houve muita diferença, dessa vez o sexo masculino se mostrou mais intolerante do que o feminino. Aproximadamente $30 \%$ dos homens votaram 1 \& 2 , contra $18 \%$ das mulheres como podemos ver no Gráfico 10 .

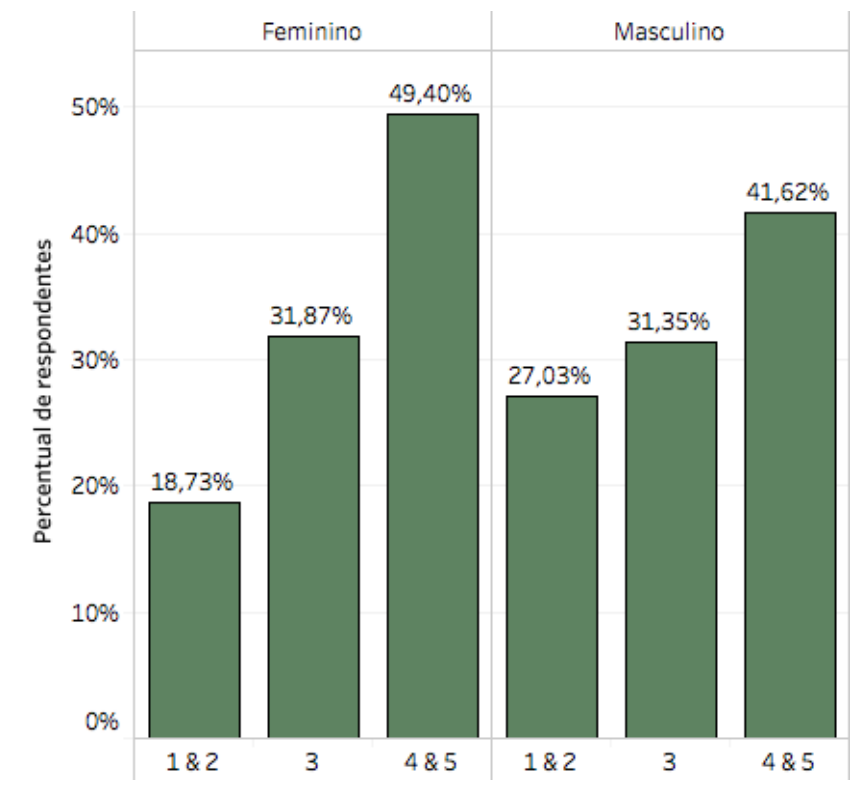

Gráfico 10 - Grau de tolerância x Sexo

Esses dados parecem indicar, que mesmo com investimento nesse tipo de comunicação com os consumidores o sexo masculino é menos tolerante que o feminino.

No cruzamento dos dados com a renda dos respondentes, não houve nenhum resultado significativo. Aproximadamente $22 \%$ tanto do grupo de classes $A$ e $B$, quanto do grupo $C, D$ e $E$ mostraram não possuir uma maior tolerância ao erro devido ao estilo de comunicação.

Isso pode ter ocorrido porque o exemplo utilizado no questionário foi relacionado a um serviço financeiro e essa classe, pode ser a mais sensível a esse tipo de serviço.

O último cruzamento feito com o grau de tolerância foi com os resultados da escala MSHS. No gráfico 11, é possível perceber que a medida que o humor vai aumentando, a tolerância ao erro vai aumentando também, ou seja, pessoas 
de péssimo humor possuem um menor grau de tolerância, respondentes de mau humor já são um pouco mais tolerantes e assim consecutivamente.

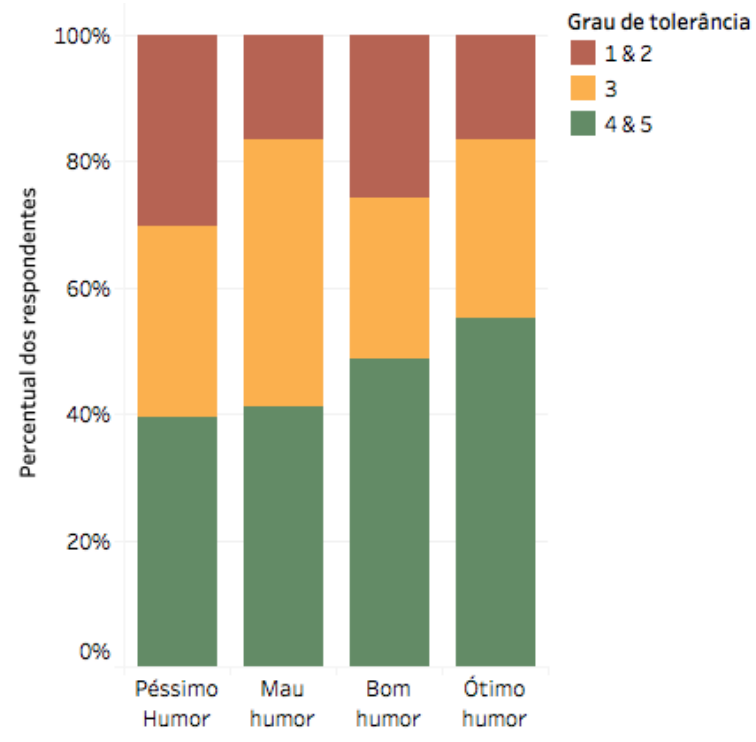

Gráfico 11 - Grau de tolerância x Humor

A terceira e última pergunta situacional, pedia para o respondente imaginar a situação em que havia sido assaltado duas vezes no mesmo mês, tendo que solicitar ao banco um novo cartão em ambas delas. Na segunda vez, junto com o cartão o banco também enviava um amuleto de boa sorte, para que essa situação não ocorresse mais. A partir daí o respondente era questionado qual era a possibilidade dele compartilhar a ação da marca em suas redes sociais e amigos. A resposta era dada em uma escala que ia de 1 a 5 , sendo 1 não indicar nenhuma chance de compartilhar e 5 alta chance de compartilhar.

Para realizar essa análise houve o agrupamento das respostas 1 e 2 como a opção de não compartilhar, 3 ficou sendo um ponto médio e as respostas 4 e 5 também foram agrupadas como a reação de compartilhar.

Analisando em um aspecto geral, mais da metade dos respondentes disseram que compartilhariam uma ação deste tipo realizada por uma empresa, como pode ser visto no Gráfico 12. 


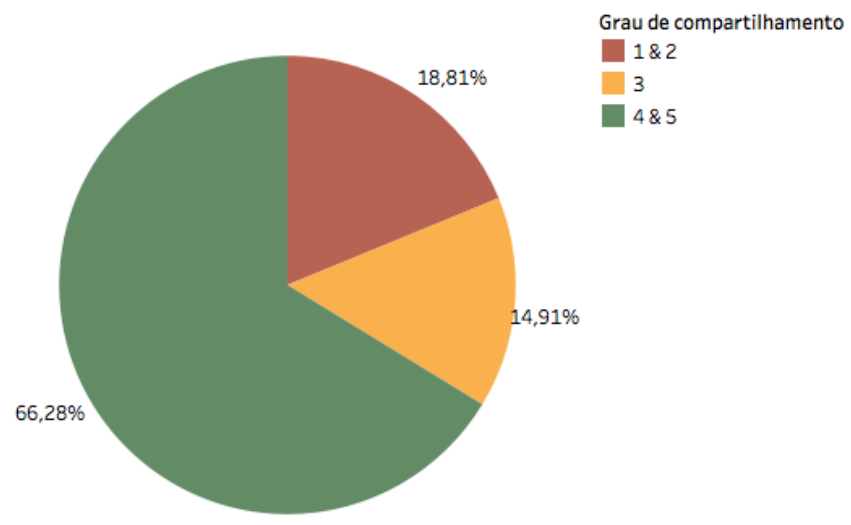

Gráfico 12 - Grau de compartilhamento geral

Esse é um dado importante para as empresas, pois investir em uma ação pontual com um cliente pode fazer com que atinjam a muitos outros através do compartilhamento nas mídias sócias, podendo até viralizar. Isso parece ser uma boa estratégia de marketing de baixo custo que para tentar alcançar um grande público.

Relacionando esses resultados com a idade dos respondentes percebe-se um padrão a partir dos 31 anos de idade. A porcentagem de pessoas que não compartilhariam vai aumentando à medida que a idade aumenta também, como pode-se observar no Gráfico 13.

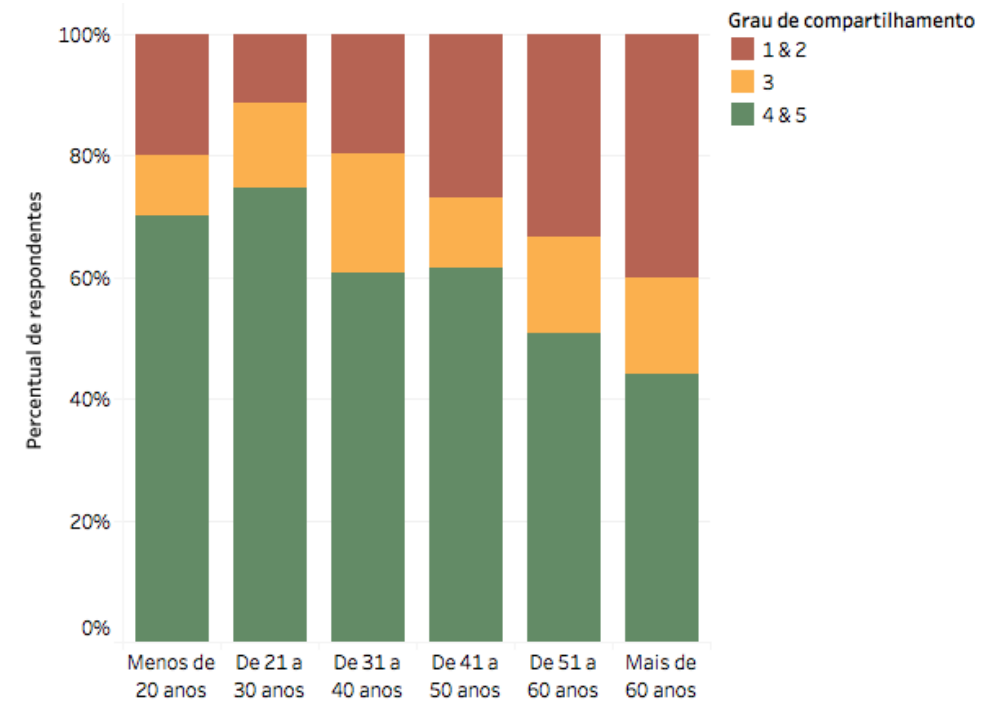

Gráfico 13 - Grau de compartilhamento x Faixa etária

Esse resultado sugere que, para empresas que querem criar impacto nas redes sociais, parece fazer sentido investir em realizar essas abordagens com um público mais jovem. Dessa forma, terão uma maior chance de que a ação seja compartilhada.

Ao fazer a comparação dos dados obtidos sobre compartilhamento com o sexo do respondente, foi obtido um resultado muito interessante. Como é 
possível ver nano Gráfico 14, aproximadamente $65 \%$ das mulheres responderam que compartilhariam a ação, contra cerca de $36 \%$ dos homens que escolheram o mesmo.

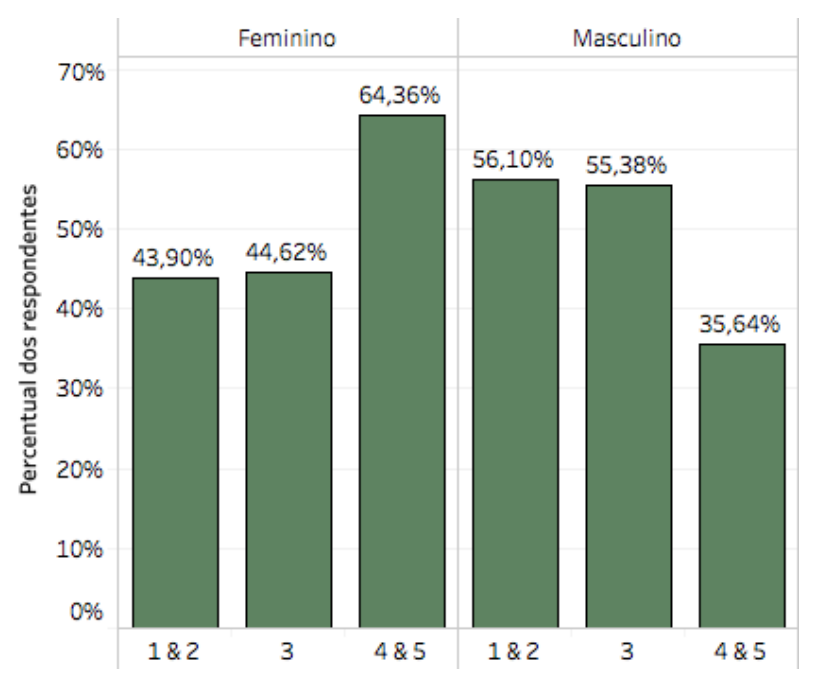

Gráfico 14 - Grau de compartilhamento x Sexo

Esse dado nos indica que, parece ser interessante para uma empresa investir em uma ação direcionada ao publico feminino, visto que mulheres possuem maior tendência a compartilhar esse tipo de conteúdo.

$\mathrm{Na}$ comparação dos resultados do grau de compartilhamento com a faixa de renda, não houve nenhum resultado significativo. Provavelmente porque as redes sociais é um meio democrático onde todas as classes circulam com tranquilidade.

Os últimos dados a serem comparados com o grau de compartilhamento é a escala MSHS. Como é possível ver no Gráfico 15, conforme o humor do respondente vai aumentando, maior é a tendência de ele compartilhar uma ação.

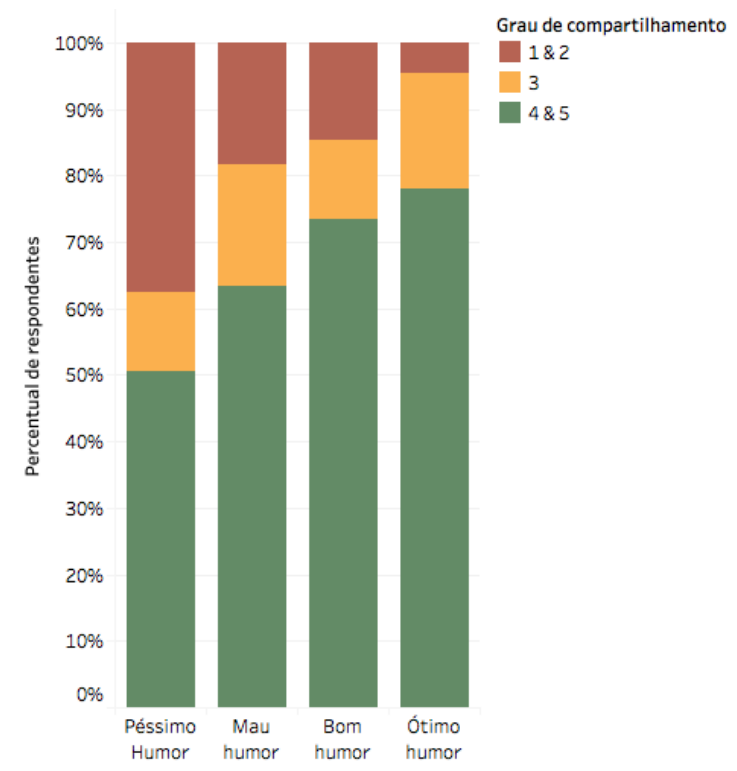

Gráfico 15 - Grau de compartilhamento x Humor 
Cerca de $50 \%$ das pessoas de péssimo humor disseram que não compartilhariam, contra $7 \%$ de pessoas de ótimo humor. Parece interessante que as marcas comecem as pesquisar sobre os tipos de humor de seus consumidores para então passarem a fazer campanhas direcionadas para cada tipo de consumidor.

A quinta pergunta do questionário foi uma escala onde os respondentes eram questionados sobre em quais situações eles acreditavam que esse tipo de interação mais descontraída e com apelo de humor poderia ocorrer. Foram exemplificadas sete situações que são: para informar novidades, para realizar cobranças, quando a empresa comete algum erro, para informar problemas, ao receber sugestões, ao receber elogios e ao prestar suporte ao consumidor. O informante poderia responder em cada uma dessas situações entre discorda totalmente, discorda, não concorda nem discorda, concorda e concorda totalmente.

Para fazer a análise dos itens discorda totalmente e discorda foram agrupados, não concorda nem discorda foi mantido como um ponto médio e os itens concorda e concorda totalmente também foram agrupados.

Analisando em um aspecto geral, os resultados podem ser observados na Tabela 1.

\begin{tabular}{|lccc|}
\hline & $\begin{array}{c}\text { Discorda } \\
\text { totalmente e } \\
\text { discorda }\end{array}$ & $\begin{array}{c}\text { Não concorda nem } \\
\text { discorda }\end{array}$ & $\begin{array}{c}\text { Concorda e } \\
\text { concorda } \\
\text { totalmente }\end{array}$ \\
\hline Para informar novidades & $16 \%$ & $15 \%$ & $69 \%$ \\
\hline Para realizar cobranças & $50 \%$ & $20 \%$ & $30 \%$ \\
\hline Quando a empresa comete algum erro & $37 \%$ & $19 \%$ & $44 \%$ \\
\hline Para informar problemas & $41 \%$ & $18 \%$ & $41 \%$ \\
\hline Ao receber sugestões & $13 \%$ & $11 \%$ & $76 \%$ \\
\hline Ao receber elogios & $10 \%$ & $9 \%$ & $81 \%$ \\
\hline Ao prestar suporte ao consumidor & $21 \%$ & $15 \%$ & $64 \%$ \\
\hline
\end{tabular}

Tabela 1 - Percentual de respondentes por situação

Pode-se observar que a maior parte dos informantes concordam que para informar novidades, quando a empresa comete algum erro, ao receber sugestões, ao receber elogios e ao prestar suporte esse tipo de comunicação poderia ocorrer. Já para informar problemas, os respondentes escolheram de forma equilibrada concordar e discordar com a abordagem. Por fim para realizar cobranças a grande maioria discorda que essa seja uma boa situação para utilizar esse tipo de abordagem. 
Esses resultados parecem ter alta relevância para as empresas, pois entender em quais momentos os clientes podem desagradar da abordagem é muito importante para o planejamento da comunicação. Existe um potencial muito grande para utilizar a comunicação personalizada com a exceção da cobrança e informação de problemas que parecem ser quesitos de muita sensibilidade para os consumidores.

Ao comparar as respostas com os demais quesitos da pesquisa não houve nenhuma diferença realmente significante no que desrespeito a sexo e classes sociais. 


\section{Conclusões e recomendações para novos estudos}

A forma de se comunicar vem ganhando novos meios com a constante evolução da tecnologia. O mundo é conectado e tudo acontece em tempo real. A partir disso as empresas precisaram se adaptar e entrar nos meios digitas para conseguir acompanhar os consumidores de forma mais acessível e menos burocrática.

O SAC 2.0, revolucionou o relacionamento com o cliente levando essa relação para dentro das mídias digitais. Para ingressar nesse universo algumas companhias passaram a se comunicar de forma mais orgânica e humana afim de ter uma maior aproximação com o cliente.

Esse trabalho pretendeu investigar como a comunicação personalizada ao cliente poderia influenciar a atitude do consumidor. $O$ foco do estudo recaiu sobre como a atitude do consumidor poderia ser influenciada com esse tipo de abordagem. Tal questão se mostra importante na medida em que cada vez mais empresas estão utilizando comunicação personalizada e conseguir entender como ter um melhor impacto com ela pode ser muito positivo, aumentando o impacto da comunicação.

Para atingir aos objetivos pretendidos realizou-se duas pesquisas, uma exploratória e outra descritiva. Na pesquisa exploratória foi feita observação da interação das empresas com os clientes nas redes sociais afim de coletar dados que auxiliassem para a construção do questionário da segunda etapa. $\mathrm{Na}$ segunda etapa foi feito um questionário, que obteve resposta de 436 informantes. Dentro da amostra haviam pessoas de ambos os sexos, diferentes classes sociais, faixas etárias e níveis de humor.

Dentro das principais questões abordadas, haviam perguntas situacionais para entender o grau de surpresa, tolerância e compartilhamento do respondente. Além de duas escalas, uma buscando compreender as situações que os informantes julgavam aceitáveis que se usasse a comunicação personalizada e outra chamada MSHS, para avaliar o nível de humor das pessoas.

Ao fazer a análise dos dados foi possível concluir que existe retorno caso uma empresa invista esforços nesse tipo de relacionamento com o cliente. A 
grande maioria dos pesquisados se surpreenderiam com a abordagem personalizada, passariam a ter uma maior tolerância a erros de uma empresa que se reportasse dessa forma e compartilhariam ações esse tipo.

Foi investigado também, através da escala MSHS, qual era o humor dos respondentes de acordo com cada situação descrita. Concluiu-se que independente do humor a grande maioria das pessoas se surpreenderiam com essa abordagem mais humana, mostrando uma abertura a uma interação com a comunicação personalizada. Já pessoas com péssimo humor são menos tolerantes a erros cometidos pela empresa do que as pessoas dos demais níveis de humor, com isso parece interessante que as empresas tenham atenção ao se comunicar dessa forma nesse caso, pois o cliente parece ser mais sensível a esse tipo de situação. Por ultimo notou-se que o grau de compartilhamento vai aumentando a medida que o nível de humor aumenta também. Isso mostra que talvez essa seja uma oportunidade para que as empresas invistam em formas de identificar clientes com o melhor humor, pois esses possuem maior tendência de compartilhar seus conteúdos.

\subsection{Sugestões e recomendações para novos estudos}

Como desdobramentos futuros, essa linha de estudo pode ser desenvolvida através de investigação sobre o nível de instrução dos informantes, essa informação pode agregar para cruzar com as outras medidas utilizadas e enriquecer mais o estudo. Outro ponto a ser estudado, é fazer a identificação de quais segmentos do mercado tem maior aceitação dos consumidores para que usem a comunicação personalizada. 


\section{Referências Bibliográficas}

CANSADO BARBOSA, Thais Aparecido; MINCIOTTI, Silvio Augusto. Serviço de atendimento ao cliente terceirizado ou próprio? Uma análise da satisfação do cliente usuário. Revista Brasileira de Gestão de Negócios, v. 9, n. 25, p. 81 95, 2007.

COUTINHO, Marcelo. A web 2.0 vai às compras. Disponível em

$<$ http://criancaeconsumo.org.br/wp-content/uploads/2017/02/134183373-A-Web2-0-vai-as-compras.pdf $>$ Rio de Janeiro, 10 mai. 2009. Acesso em: 11 de setembro de 2017.

DEL ROWE, S. How to succeed in real-time marketing: connecting with customers at critical moments in the buying process is becoming the new imperative. CRM Magazine, mai. 2016. Disponível em: $<$ http://www.destinationcrm.com/Articles/Editorial/Magazine-Features/How-toSucceed-in-Real-Time-Marketing-110830.aspx>.Acesso em:10 de setembro de 2017.

Digital Marketing Glossary. Whats is Real-time marketing definition. Disponível em: <http://digitalmarketing-glossary.com/What-is-Real-timemarketing-definition> 12 dez. 2014. Acesso em: 15 de setembro. 2017.

EVALDT, SC. Marketing em tempo real como estratégia para engajar clientes : a construção de relacionamento com usuários na fanpage de 0 Boticário. Rio Grande do Sul, 30 jun. 2015.

JOSÉ, $\mathrm{H}$; PARREIRA, P. Adaptação para português da Escala Multidimensional do Sentido de Humor. Portugal, Europe, 2012.

KOTLER, P. KELLER, K. L. Administração de marketing. São Paulo: Pearson Education do Brasil, 2012.

KOTLER, P. AMStRONG, G. Princípios de marketing. São Paulo: Pearson Education do Brasil, 2015.

MADRUGA, Roberto. Gestão moderna de Call Center e telemarketing. Editora Atlas SA, 2000.

MANCINI, Lucas. Call Center: estratégia para vencer. Summus Editorial, 2001.

Rafael Barreiros, P. Atitude do Consumidor: Estrutura dos Modelos Teóricos. Revista Brasileira de Marketing, Vol 9, n 2, p. 41-58, 2010.

RIBEIRO, R. B., \& SOARES, I. (2015). Marketing/ Marketing Science. The Wiley Black well Encyclopedia of Consumption and Consumer Studies, First Edition.

SAMARA, Beatriz Santos; DE BARROS, José Carlos. Pesquisa de marketing: conceitos e metodologia. Pearson Prentice Hall, 200 
SILVA, Hélcia Daniel da. Humor nas propagandas televisivas: um olhar qualitativo sobre as percepções dos consumidores. São Leopoldo, 2010.

SOLOMON, Miachael R. O comportamento do consumidor: Comprando, possuindo e sendo. Porto Alegre: Bookman, 2016.

SCHIFFMAN ,Leon G. KANUK, Leslie Lazar. Comportamento do Consumidor. Rio de Janeiro: Editora LTC, 2000

Terra, Carolina Frazon. "O que as organizações precisam fazer para serem bem vistas nas mídias sociais sob a ótica da Comunicação Organizacional e das Relações Públicas." V Congresso Científico de Comunicação Organizacional e Relações Públicas ABRAPCORP, São Paulo. 2011.

Tiago Savi, M; Jane lara Pereira da, C; Aline Regina dos, S. O Telemarketing Ativo na Perspectiva do Consumidor. Revista Brasileira de Marketing, Vol $8, n$ 2, p. 98-115, 2010.

THORSON, James A.; POWELL, F. C. Sense of humor and dimensions of personality. Journal of clinical Psychology, v. 49, n. 6, p. 799-809, 1993. 


\section{Anexo 1}

\begin{tabular}{|c|c|c|c|c|c|c|c|c|c|c|c|c|c|}
\hline \multirow[t]{2}{*}{ 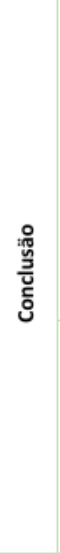 } & 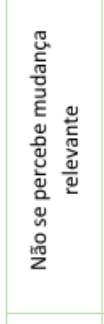 & 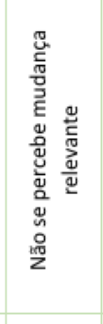 & 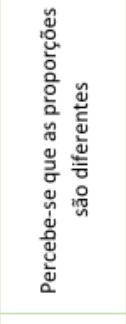 & 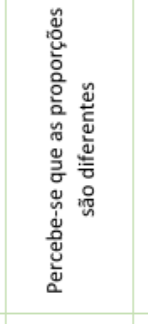 & 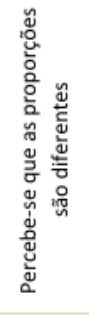 & 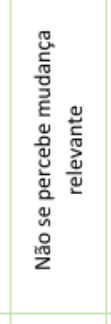 & 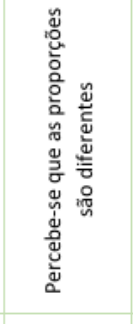 & 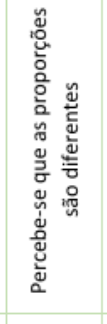 & 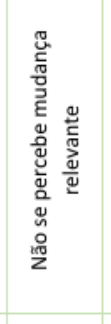 & 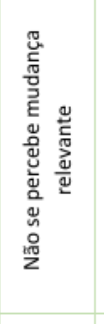 & 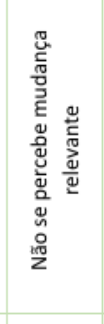 & 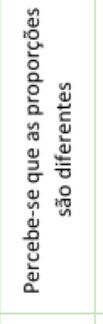 & 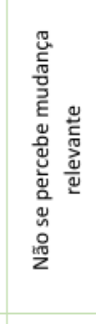 \\
\hline & 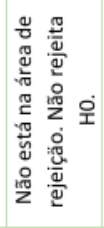 & 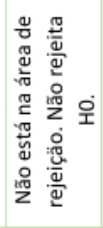 & 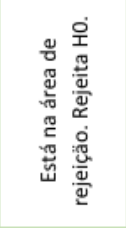 & 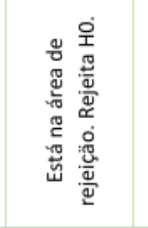 & 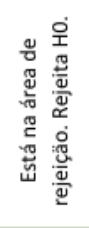 & 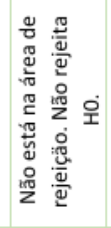 & 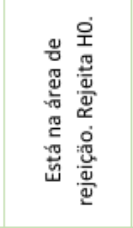 & 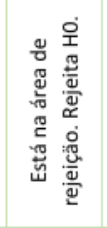 & 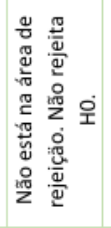 & 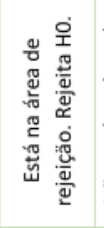 & 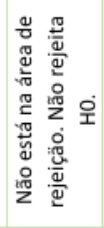 & 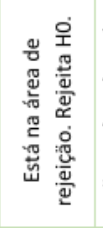 & 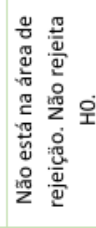 \\
\hline 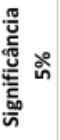 & 㟢 & 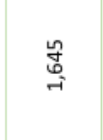 & 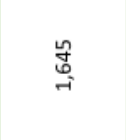 & 柋 & 忌 & 岁 & 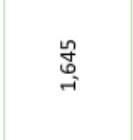 & 点 & 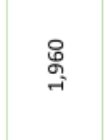 & $\underset{-i}{\stackrel{q}{G}}$ & 点 & $\underset{-i}{\stackrel{q}{G}}$ & 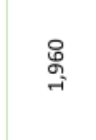 \\
\hline 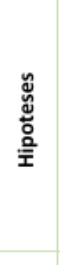 & 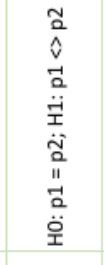 & 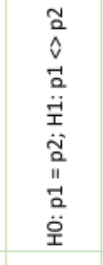 & 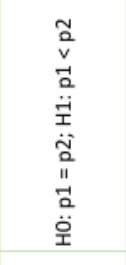 & 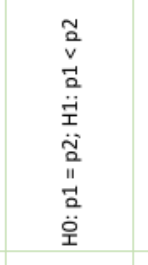 & 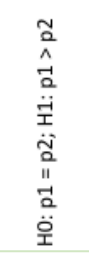 & 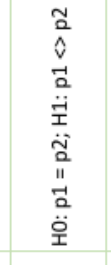 & 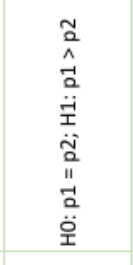 & 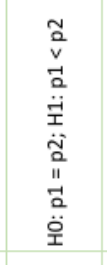 & 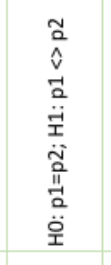 & 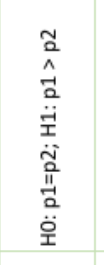 & 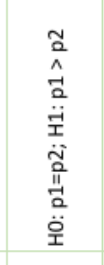 & 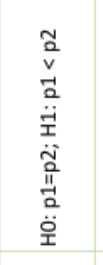 & 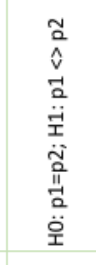 \\
\hline 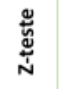 & 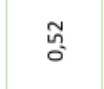 & 守 & $\underset{\mathcal{T}}{\tilde{\tau}}$ & 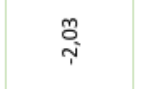 & $\underset{\sim}{\sim}$ & $\underset{F}{\mathscr{F}}$ & वे & $\underset{\mathcal{d}}{\text { f }}$ & : & 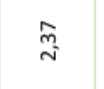 & $\stackrel{\infty}{\infty} \underset{\circ}{\infty}$ & 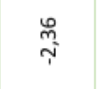 & 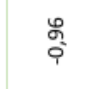 \\
\hline$\simeq$ & $\stackrel{\leftrightarrow}{\sim}$ & 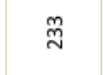 & gे & $\stackrel{\leftrightarrow}{\sim}$ & gे & $\ddot{\dddot{m}}$ & $\stackrel{\leftrightarrow}{~}$ & ฏ & $\stackrel{\dddot{m}}{\sim}$ & $\vec{山}$ & $\overrightarrow{\vec{n}}$ & $\vec{\Phi}$ & $\vec{\unlhd}$ \\
\hline$\vec{E}$ & $\overrightarrow{\vec{N}}$ & $\stackrel{\sim}{\sim}$ & ஓे & $\overrightarrow{\tilde{N}}$ & g & $\stackrel{\text { @ }}{\text { @ }}$ & $\overrightarrow{\vec{n}}$ & g & 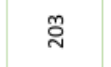 & $\stackrel{\mathscr{\sigma}}{\sim}$ & $\stackrel{\leftrightarrow}{\sim}$ & $\stackrel{\leftrightarrow}{\sim}$ & $\stackrel{\leftrightarrow}{\sim}$ \\
\hline$\simeq$ & 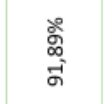 & 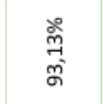 & 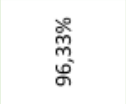 & $\begin{array}{l}\text { ळ. } \\
\stackrel{\circ}{\text { i }}\end{array}$ & 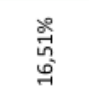 & $\begin{array}{l}\text { స్ } \\
\text { ఫे }\end{array}$ & 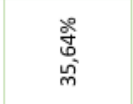 & 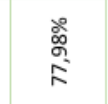 & 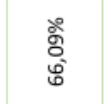 & $\begin{array}{l}\text { స̊ } \\
\text { ồ }\end{array}$ & 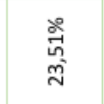 & $\begin{array}{l}\text { \%े } \\
\text { ఏे }\end{array}$ & $\begin{array}{l}\text { 今. } \\
\text { o. } \\
\text { d. }\end{array}$ \\
\hline$\vec{a}$ & 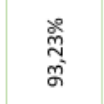 & $\begin{array}{l}\text { స్ స్ } \\
\text { స్ }\end{array}$ & సั స్ & 誉 & 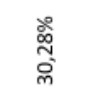 & 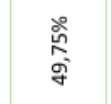 & 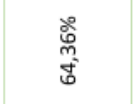 & 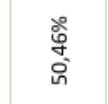 & 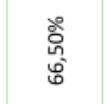 & 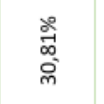 & 总 & 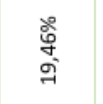 & $\begin{array}{l}\stackrel{\circ}{\circ} \\
\text { ì }\end{array}$ \\
\hline 总 & 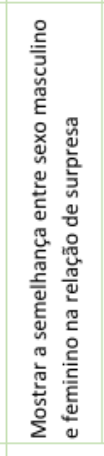 & 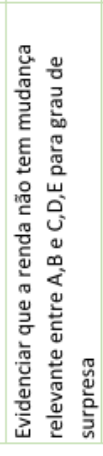 & 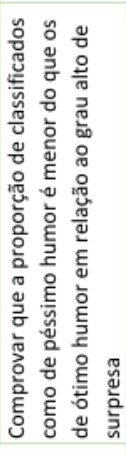 & 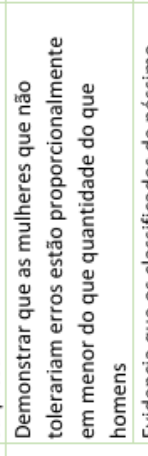 & 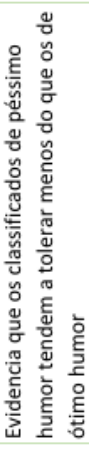 & 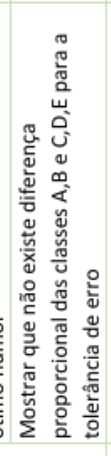 & 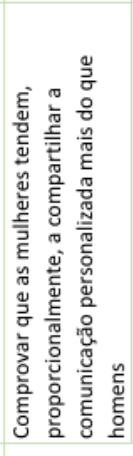 & 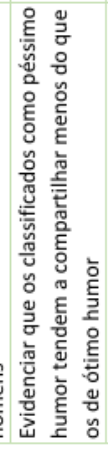 & 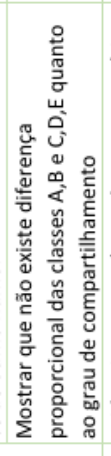 & 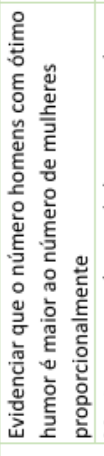 & 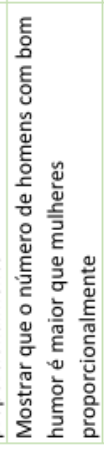 & 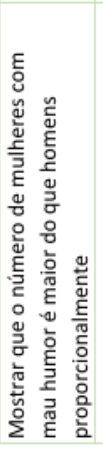 & 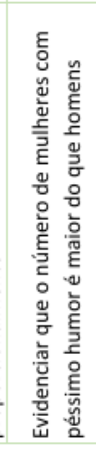 \\
\hline $\begin{array}{l}\text { 递 } \\
\text { 离 }\end{array}$ & & - & & & $\sim$ & & & m & & & & & \\
\hline
\end{tabular}




\section{Anexo 2}

Hoje em dia muitas empresas buscam formas não convencionais de chegar a nós clientes. Somos abordados por todos os meios: redes sociais, aplicativos de mensagem e até cartas escritas a mão. Essas são apenas algumas formas utilizadas de nos chamar atenção.

Dá uma olhada só nesse exemplo da Netflix interagindo com os clientes de forma jovem e descontraída nas redes sociais:

vez.

Só acho que deveriam lançar os episódios todos de uma

To vendo Voyager pra compensar o tempo de lançamento do discovery Curtir - Responder - 16 - 23 de outubro às 11:54

D Netflix $\odot$ Eu preciso respeitar a exibiçăo nos Estados Unidos. Por isso esse formato. Mas pelo menos isso ressignificou nossa segunda-feira, vai?

Curtir-Responder - $\boldsymbol{O} \boldsymbol{S} 68 \cdot 23$ de outubro às 11:57

$\hookrightarrow$ Ver mais respostas

É sobre isso que vamos falar aqui. Não se preocupe! Esse nosso papo não irá durar mais que 10 minutos e as respostas desse questionário são anônimas. Elas serão usadas apenas para criar estatísticas, não sendo possível achar o autor de determinada resposta.

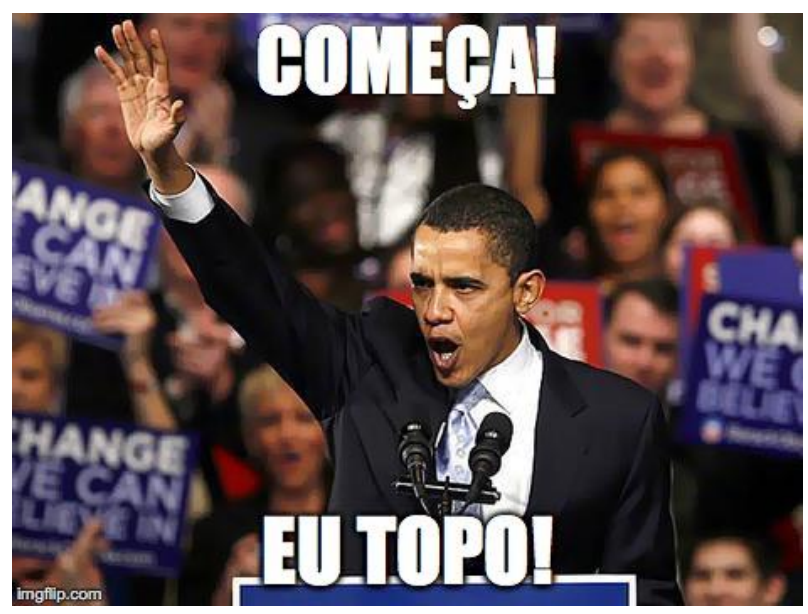


Questão 1: Imagine a seguinte situação: você tem seu cartão de crédito mastigado pelo seu cachorro e pede para o seu banco lhe enviar um novo por esse motivo. Eles te mandam um novo cartão com um presente para seu pet e uma carta feita a mão assinada por toda equipe. Em uma escala de 5 pontos, na qual 1 indica não se surpreender e 5 se surpreender muito. $O$ quanto você se surpreenderia com uma abordagem como essa?
1
2
3
4
5
( )
( )
( )
( )

Questão 2: E se esse mesmo banco cometesse algum erro com você, como por exemplo cobrar duas vezes um mesmo valor? Em uma escala de 5 pontos, na qual 1 indica não tolerar e 5 alta tolerância. $O$ quanto você seria mais tolerante ao erro cometido por uma empresa que se preocupa em falar com você de forma personalizada e mais humana ao invés de seguir padrões?

$\begin{array}{lcccc}1 & 2 & 3 & 4 & 5 \\ (\mathrm{l}) & (\mathrm{)} & (\mathrm{l}) & (\mathrm{)} & (\mathrm{)}\end{array}$

Questão 3: Agora imagine que você foi assaltado duas vezes em um mesmo mês, tendo que solicitar ao seu banco um novo cartão em ambas vezes. Na segunda vez, junto com o cartão você recebe também um amuleto de boa sorte, para que isso não ocorra mais. Em uma escala de 5 pontos, na qual 1 indica nenhuma chance e 5 alta chance. Qual a possibilidade de você compartilhar essa ação da empresa em suas redes sociais e amigos?
1
2
3
4
5
( )
( )
( )
( )
( )

Questão 4: Quais desses meios de comunicação você costuma utilizar? (Assinale mais de uma opção, se necessário).
( ) Facebook
( ) Instagram
( ) Twitter
( ) Snapchat
( ) Whatsapp
( ) E-mail
( ) SMS
( ) Telefone 
Questão 5: Eu acredito que essa interação com uma linguagem mais descontraída e com apelo de humor deve ocorrer:

\begin{tabular}{l|ccccc} 
& Discorda & $\begin{array}{l}\text { Discorda } \\
\text { totalmente }\end{array}$ & $\begin{array}{r}\text { Não concorda } \\
\text { em discorda }\end{array}$ & $\begin{array}{c}\text { Concorda } \\
\text { Concorda } \\
\text { totalmente }\end{array}$ \\
\hline Para informar novidades & $($ ) & $($ ) & $($ ) & $($ ) & $($ ) \\
Para realizar cobranças & $($ ) & $($ ) & $($ ) & $($ ) & $($ ) \\
Quando a empresa comete algum erro & $($ ) & $($ ) & $($ ) & $($ ) & $($ ) \\
Para informar problemas & $($ ) & $($ ) & $($ ) & $($ ) & $($ ) \\
Ao receber sugestões & $($ ) & $($ ) & $($ ) & $($ ) & $($ ) \\
Ao receber elogios & $($ ) & $($ ) & $($ ) & $($ ) & $($ ) \\
Ao prestar suporte ao consumidor & $($ ) & $($ ) & $($ ) & $($ ) & $($ )
\end{tabular}

Questão 6: Agora vou fazer algumas perguntas para saber mais sobre o seu senso de humor.

\begin{tabular}{|c|c|c|c|c|c|}
\hline & $\begin{array}{l}\text { Discorda } \\
\text { totalmente }\end{array}$ & Discorda & $\begin{array}{l}\text { Não concorda } \\
\text { nem discorda }\end{array}$ & Concorda & $\begin{array}{l}\text { Concorda } \\
\text { totalmente }\end{array}$ \\
\hline $\begin{array}{l}\text { Eu sou visto pelos meus amigos } \\
\text { como uma pessoa com senso de humor }\end{array}$ & () & $($ ) & $($ ) & () & $($ ) \\
\hline $\begin{array}{l}\text { Eu consigo dizer coisas que fazem as } \\
\text { pessoas rirem }\end{array}$ & ( ) & ( ) & ( ) & () & () \\
\hline As coisas que eu falo divertem os outros & $($ ) & $($ ) & ( ) & ( ) & $($ ) \\
\hline $\begin{array}{l}\text { As pessoas olham para mim para que eu } \\
\text { diga coisas engraçadas }\end{array}$ & ( ) & ( ) & $($ ) & ( ) & ( ) \\
\hline $\begin{array}{l}\text { Eu uso o humor para entreter os meus } \\
\text { amigos }\end{array}$ & $($ ) & ( ) & ( ) & $($ ) & $($ ) \\
\hline $\begin{array}{l}\text { Estou confiante de que consigo fazer } \\
\text { outras pessoas rirem }\end{array}$ & () & $($ ) & ( ) & ( ) & $($ ) \\
\hline $\begin{array}{l}\text { Outras pessoas me dizem que eu digo } \\
\text { coisas engraçadas }\end{array}$ & ( ) & ( ) & ( ) & ( ) & $($ ) \\
\hline $\begin{array}{l}\text { Ás vezes me vem à cabeça piadas ou } \\
\text { histórias engraçadas }\end{array}$ & $($ ) & () & ( ) & ( ) & $($ ) \\
\hline $\begin{array}{l}\text { Eu consigo surpreender e fazer as } \\
\text { pessoas gargalharem }\end{array}$ & $($ ) & $($ ) & ( ) & () & $($ ) \\
\hline $\begin{array}{l}\text { Eu consigo aliviar uma situação de tensão } \\
\text { dizendo algo engraçado }\end{array}$ & $(\mathrm{l})$ & ( ) & ( ) & ( ) & ( ) \\
\hline $\begin{array}{l}\text { Eu até consigo ter algum controle sobre } \\
\text { um grupo quando uso humor }\end{array}$ & () & ( ) & ( ) & ( ) & () \\
\hline O humor me ajuda a lidar com as coisas & $($ ) & ( ) & ( ) & ( ) & ( ) \\
\hline $\begin{array}{l}\text { Piadas inteligentes ou uso de humor me } \\
\text { ajudam a lidar com situações difíceis }\end{array}$ & ( ) & ( ) & ( ) & ( ) & ( ) \\
\hline $\begin{array}{l}\text { Lidar com as coisas com humor é uma } \\
\text { elegante forma de adaptação }\end{array}$ & ( ) & ( ) & ( ) & ( ) & ( ) \\
\hline $\begin{array}{l}\text { Tentar lidar com situações através do uso } \\
\text { do humor é realmente estúpido }\end{array}$ & ( ) & ( ) & ( ) & ( ) & ( ) \\
\hline $\begin{array}{l}\text { O humor é uma péssima forma de lidar } \\
\text { com as coisas }\end{array}$ & ( ) & ( ) & ( ) & ( ) & ( ) \\
\hline
\end{tabular}




\begin{tabular}{|c|c|c|c|c|}
\hline $\begin{array}{l}\text { Usar o humor ajuda com que eu me sinta } \\
\text { mais à vontade }\end{array}$ & $($ ) & $($ ) & () & () \\
\hline $\begin{array}{l}\text { Eu consigo usar piadas inteligentes para } \\
\text { me ajudar a adaptar a muitas situações }\end{array}$ & () & $($ ) & $($ ) & $($ ) \\
\hline $\begin{array}{l}\text { Eu aprecio as pessoas que são } \\
\text { bem humoradas }\end{array}$ & $($ ) & $($ ) & $(\mathrm{)}$ & $($ ) \\
\hline Eu gosto de uma boa piada & ( ) & ( ) & ( ) & ( ) \\
\hline $\begin{array}{l}\text { Chamar alguém de "comediante" é um } \\
\text { verdadeiro insulto }\end{array}$ & () & () & () & ( ) \\
\hline Eu não gosto de pessoas engraçadas & () & () & () & $($ ) \\
\hline Pessoas que contam piadas são chatas & ( ) & ( ) & ( ) & ( ) \\
\hline $\begin{array}{l}\text { Fico desconfortável quando alguém conta } \\
\text { Piadas }\end{array}$ & () & () & () & $($ ) \\
\hline
\end{tabular}

Agora já estamos quase acabando, só preciso de mais algumas informações sobre você.

Questão 7: Qual o seu sexo?

( ) Feminino

( ) Masculino

Questão 8: Quantos anos você tem?
( ) Menos de 20 anos
( ) De 20 a 30 anos
( ) De 31 a 40 anos
( ) De 41 a 50 anos
( ) Mais de 60 anos

Questão 9: Somando a sua renda com a renda das pessoas que moram com você, quanto é, aproximadamente, a renda familiar mensal?
( ) Até $\mathrm{R} \$ 1.874,00$
( ) De $R \$ 1.874,01$ a $R \$ 3.748,00$
( ) De $R \$ 3.748,01$ a $R \$ 9.370,00$
( ) De $R \$ 9.370,00$ a $R \$ 18.840,00$
( ) $\mathrm{R} \$ 18.840,01$ ou mais

Muito obrigada por participar e me ajudar a chegar mais perto do meu diploma!

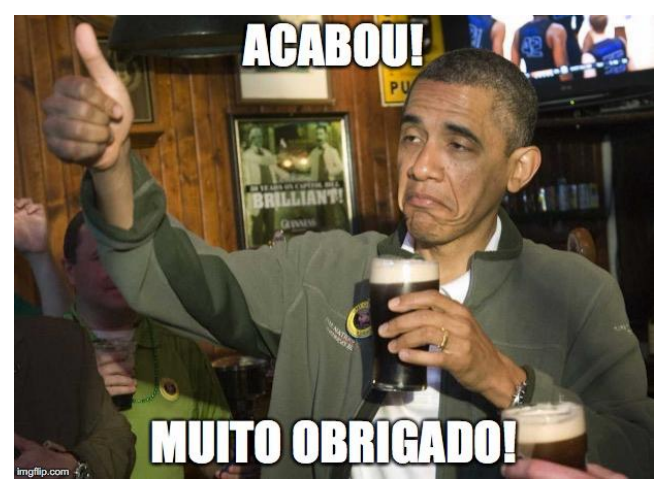

